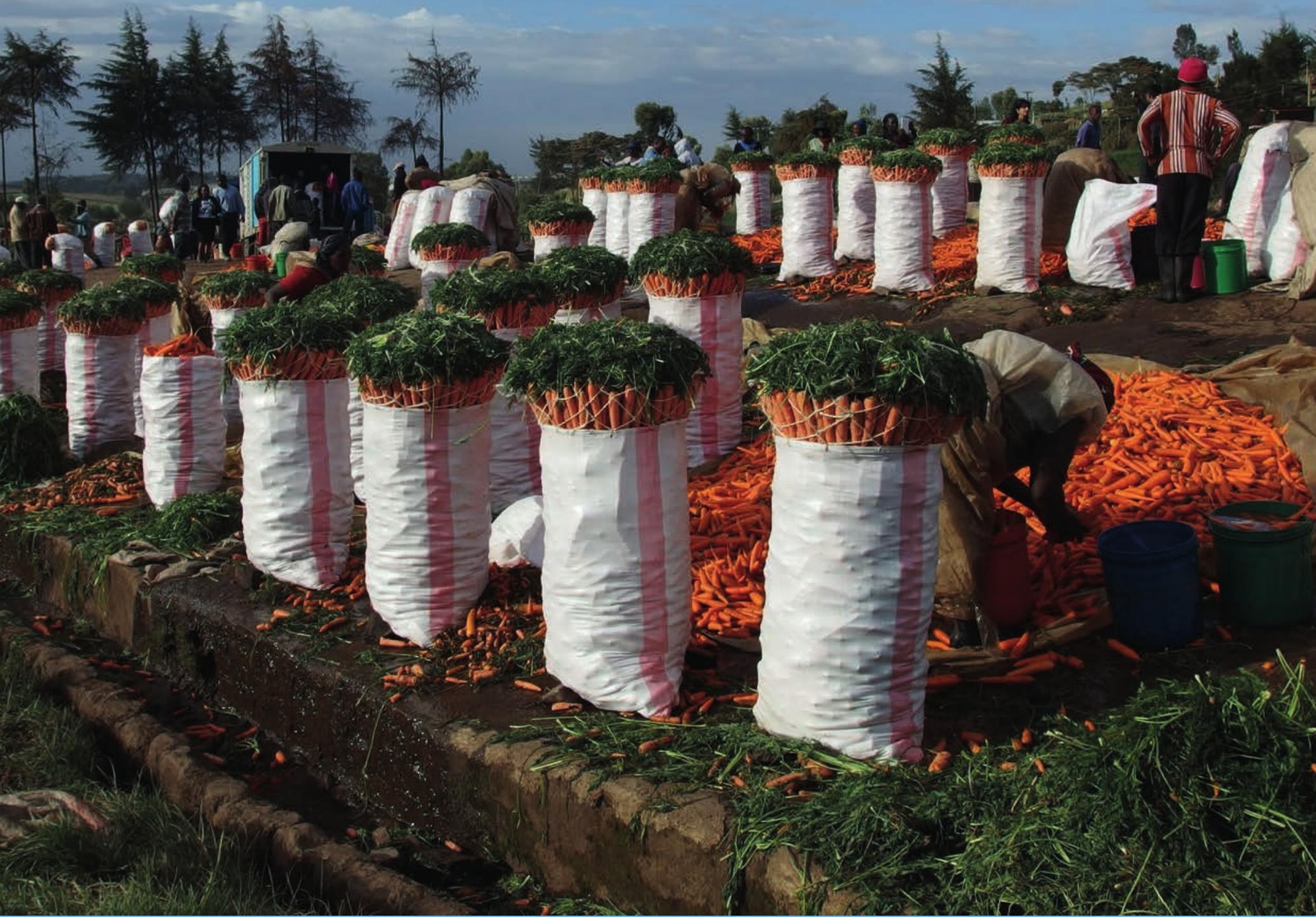

\title{
Piloting a fresh fruit and vegetables market to deliver high quality, safe food products
}

Reflections and lessons learned

Joyce Gema, Jessica W. Koge, John Keige, Indira Moreno-Echeverri, Carolyne Kipkoech, Emmanuel Matsaba,

Catherine Kilelu, John Wesonga, Irene Koomen

WAGENINGEN

UNIVERSITY \& RESEARCH 



\section{Piloting a fresh fruit and vegetables market to deliver high quality, safe food products}

Reflections and lessons learned

Joyce Gema ${ }^{1}$, Jessica W. Koge ${ }^{2}$, John Keige ${ }^{1}$, Indira Moreno-Echeverri ${ }^{3}$, Carolyne Kipkoech ${ }^{4}$, Emmanuel Matsaba ${ }^{4}$, Catherine Kilelu², John Wesonga ${ }^{4}$, Irene Koomen ${ }^{3}$

\section{Tradecare Africa}

2 African Centre for Technology Studies

3 Wageningen University \& Research

4 Jomo Kenyatta University of Agriculture Technology

This research was conducted by the 3R Kenya project, commissioned and funded by the Embassy of the Kingdom of the Netherlands in Nairobi, Kenya, within the framework of the Agriculture and Food \& Nutrition Security programme.

Wageningen Centre for Development Innovation

Wageningen, July 2020

Report WCDI-20-117

3R Report 016 
Gema J., Koge J., Keige J., Moreno-Echeverri I., Kipkoech C., Matsaba E., Kilelu C., Wesonga J., Koomen I., 2020. Piloting a fresh fruit and vegetables market to deliver high quality, safe food products; Reflections and lessons learned. Wageningen Centre for Development Innovation, Wageningen University \& Research. Report WCDI-20-117/3R Report 016. Wageningen.

\section{R Kenya Project}

The 3R Kenya (Resilient, Robust, Reliable - From Aid to Trade) project is a learning initiative supported under the Agriculture and Food and Nutrition Security (FNS) programme of the Embassy of the Kingdom of the Netherlands. 3R Kenya seeks to assess evidence and lessons from FNS and other related programmes that support competitive, market-led models in spurring agricultural development. It focuses on the aquaculture, dairy and horticulture sectors. 3R Kenya is executed at a time when the Dutch government's bilateral relations in Kenya are transitioning from a focus on Aid to a focus on Trade to enhance the development of agri-food sectors. Through evidence generation and stakeholder dialogue, $3 R$ seeks to contribute to an understanding of effective conditions for sustainable inclusive trade for transforming agri-food sectors to be resilient, robust and reliable.

\section{Rs:}

Resilient: dynamic and adaptive capacities that enable agents and systems to adequately respond to changing circumstances

Robust: systematic interactions between agents that enable them to adjust to uncertainties within the boundaries of their initial configuration

Reliable: the ability of a system or component to perform its functions under changing conditions for a specified period of time, to create opportunities for (inter)national trade.

Keywords: fresh fruit and vegetables, horticulture, traceability, certification

This report can be downloaded for free at https://doi.org/10.18174/525148 or at www.wur.eu/cdi (under publications).

(C) 2020 Wageningen Centre for Development Innovation, part of the Stichting Wageningen Research. P.O. Box 88, 6700 AB Wageningen, The Netherlands. T + 31 (0)317 4868 00, E info.cdi@wur.nl, www.wur.eu/cdi.

\section{(cc) BY-NC}

The Wageningen Centre for Development Innovation uses a Creative Commons Attribution 4.0 (Netherlands) licence for its reports.

The user may copy, distribute and transmit the work and create derivative works. Third-party material that has been used in the work and to which intellectual property rights apply may not be used without prior permission of the third party concerned. The user must specify the name as stated by the author or licence holder of the work, but not in such a way as to give the impression that the work of the user or the way in which the work has been used are being endorsed. The user may not use this work for commercial purposes.

The Wageningen Centre for Development Innovation accepts no liability for any damage arising from the use of the results of this research or the application of the recommendations.

Report WCDI-20-117/3R Report 016

Photo cover: Irene Koomen 


\section{Contents}

2.1 Aim and objectives

2.3 Methodology

$\begin{array}{lll}3.1 & \text { Identifying and enlisting potential actors } & 19\end{array}$

$\begin{array}{lll}3.2 & \text { Developing product prototypes } & 20\end{array}$

$\begin{array}{lll}3.3 & \text { Setting prices and volume projections } & 21\end{array}$

3.4 Promoting viable production models and suitable service delivery models to ensure traceable products

$\begin{array}{lll}4.1 & \text { Farmers } & 27\end{array}$

$\begin{array}{lll}4.1 .1 & \text { Seed source and selection } & 27\end{array}$

$\begin{array}{ll}4.1 .2 & \text { Soil management }\end{array}$

$\begin{array}{ll}4.1 .3 \text { Soil and water testing } & 28\end{array}$

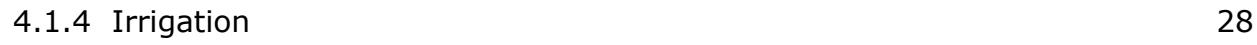

4.1.5 Pest and disease control $\quad 28$

4.1.6 Pesticide container disposal $\quad 29$

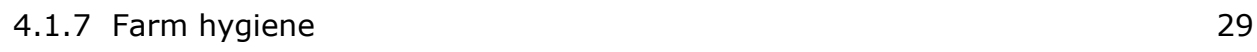

4.1.8 Post-harvest handling 29

4.1.9 Marketing $\quad 29$

4.1.10localg.a.p. implementation/training and technical support 29

4.1.11 Information literacy $\quad 30$

$\begin{array}{lll}4.2 & \text { Transport } & 30\end{array}$

$\begin{array}{ll}4.2 .1 \text { Collection } & 30\end{array}$

4.2.2 Loading, offloading and packaging $\quad 30$

4.2.3 Transfer and delivery $\quad 31$

4.2.4 Handling facilities and hygiene $\quad 31$

4.2.5 Record-keeping 31

4.2.6 Communication, marketing and customer care $\quad 31$

4.3 Pack houses $\quad 32$

4.3.1 Receiving of product and quality check 32

4.3.2 Sorting and grading $\quad 32$

4.3.3 Product handling and storage $\quad 32$

4.3.4 Product dispatch $\quad 32$

4.3.5 Hygiene and sanitation 33

4.3.6 Pest control 33

4.3.7 Waste management $\quad 33$ 
4.4 Grocery stores 33

4.4.1 Supply order placement 33

4.4.2 Packing and display 33

4.4.3 Pricing $\quad 34$

4.4.4 Hygiene and quality $\quad 34$

4.4.5 Payment 34

4.4.6 Customer service $\quad 34$

4.5 Consumers $\quad 34$

4.5.1 Supply of produce $\quad 34$

$\begin{array}{ll}4.5 .2 \text { Pricing } & 34\end{array}$

$\begin{array}{ll}4.5 .3 \text { Food safety } & 34\end{array}$

$5 \quad$ Discussion and conclusions $\quad 35$

5.1 Catalysing a domestic market for traceable and safe fresh fruit and vegetables 35

5.2 Contextualizing standards for the domestic fresh fruit and vegetables value chain $\quad 35$

$\begin{array}{lll}5.3 & \text { Conclusions } & 36\end{array}$

$\begin{array}{lr}\text { References } & 39\end{array}$

$\begin{array}{llr}\text { Appendix } 1 & \text { Product specifications }\end{array}$

$\begin{array}{lll}\text { Appendix } 2 & \text { Volumes project for the different products per region } & 43\end{array}$

$\begin{array}{llr}\text { Appendix } 3 & \text { Survey Questionnaires } & 45\end{array}$ 


\section{Acknowledgements}

We would like to thank all the people who participated in this action research, especially the farmers, transporters and grocery store keepers who were part of the pilot. And Ruth Davies for excellent editing.

This work was part of the $3 R$ project, funded by the Embassy of the Kingdom of the Netherlands in Kenya. 


\section{List of abbreviations and acronyms}

$\begin{array}{ll}\text { ACTS } & \text { African Centre for Technology Studies } \\ \text { CAN } & \text { calcium ammonium nitrate } \\ \text { COLEACP } & \text { Contact Europe-Africa-Caribbean-Pacific Liaison Committee } \\ \text { DAP } & \text { diammonium phosphate } \\ \text { FFV } & \text { fresh fruit and vegetables } \\ \text { GAP } & \text { good agricultural practices } \\ \text { HCD } & \text { Horticultural Crops Directorate } \\ \text { HTS } & \text { Horticulture Traceability System } \\ \text { ISO } & \text { International Organization of Standardization } \\ \text { JKUAT } & \text { Jomo Kenyatta University of Agriculture and Technology } \\ \text { KEPHIS } & \text { Kenya Plant Health Inspectorate Service } \\ \text { KES } & \text { Kenya Shilling } \\ \text { MT } & \text { megaton } \\ \text { RCA } & \text { React Cert Africa } \\ \text { WUR } & \text { Wageningen University \& Research }\end{array}$




\section{Summary}

Stimulating a market system that seeks to offer food safety assurance as its value proposition is innovative in the domestic fresh fruit and vegetables (FFV) market in Kenya. This pilot aimed to test such a market, anchored on the diffusion of good practices from certified export-oriented farmers to markets that are responsive to food safety concerns through traceable production, handling and trade. Poor food quality and safety were identified threats and uncertainties that impair the Kenyan horticulture sector from being ready for trade instead of aid.

The pilot aimed to validate the hypothesis that farmers who produced high quality FFV that met stricter food safety standards could be linked with the identified market segment interested in buying those products. The pilot concept aimed to work with early adopters to explore opportunities to integrate food safety standards, including traceability, in the domestic FFV market. Specifically, we explored the opportunities of helping farmers groups adopt localg.a.p. certification, which is a stepping stone towards having GLOBALG.A.P. certification.

This study provided insights on the different steps needed to connect FFV with market segments, and specifically the low- and middle income consumers in Nairobi, interested in higher levels of assurance in terms of food safety. The main findings are that localg.a.p. is a suitable standard for semicommercial horticulture farmers but that ready to use traceability systems such as eProd do not fully support the domestic horticulture sector (yet). During implementation of the pilot traceability was done through the manual labelling based on the localg.a.p. bookmarking system. For the purpose of the pilot this worked adequately but did not address the challenge of a traceability suitable for the domestic horticulture value chain.

Building trust and business relations between the value chain actors as a pre-requisite for the value proposition of traceable and safe FFV for the domestic consumer to work, is a lengthy process that goes beyond a pilot. However, the pilot has shown the proof of concept that providing the domestic market with traceable and safe FFV is a viable concept.

This study was part of the $3 R$ project. It sought to generate evidence and lessons from programmes that are supported by the Embassy of the Kingdom of the Netherlands on competitive, market-led models in spurring agricultural development. 


\section{Introduction}

The domestic horticulture sector in Kenya is transforming in response to the changing diets of a growing population that is increasingly urbanized and middle class. Higher demand for fresh fruit and vegetables (FFV) can be seen by comparing 2018 with 2017 horticulture data: the total area under production in 2018 was 399,775 ha, production was 6,283,699 MT and the value was KES 122,108 billion, increases of $4.3 \%, 6.8 \%$ and $8.4 \%$ respectively compared to 2017 (AFA, 2019). In 2017, 87,240 MT of vegetables valued at 24,065 million KES and 56,945 MT of fruit valued at 9,009 million KES were exported (AFA, 2019). The domestic market presents a significant opportunity for sustainable growth, making it attractive for investment.

A quick scan of the horticulture sector (Matui et al., 2016) indicated that a fragmented domestic market is one of the most limiting factors for the development of the domestic horticulture sector in Kenya. The fragmentation is characterised by weak relations in supply chains contributing to high price fluctuations and incidence of food waste, in addition to weak governance mechanisms that should assure consumers that produce is safe. Studies have found high levels of contamination by various hazards in both informal and formal domestic market channels of FFV (Inonda et al., 2015; Kutto et al., 2011; Onyango and Kunyanga, 2013; Route to Food, 2019; Yen et al., 2018). However, other studies have shown that many farmers produce FFV for the export market that do meet the high quality, legal and voluntary standards (Gema et al., 2018; Lenné et al., 2005; Mithöfer et al., 2008).

Through media reports and research publications, the domestic market is gradually becoming informed on safety issues related to the consumption of fresh produce (e.g. Route to Food, 2019). Thus, food safety is increasingly of national concern. The introduction of the food safety standard (KS1758-2:2016) supported by the Horticulture Traceability System (HTS) offers opportunities in the domestic FFV market (Chemeltorit et al., 2018; Gema et al., 2018). The need for a national food safety assurance system is creating new market opportunities for farmers and grocery stores to create better organized supply chains that support relationship building and information flow up and down the chain.

Currently the main market segments for FFV are the wet wholesale and retail markets, which account for over $85 \%$ of FFV volume (Gema et al., 2018). However, different market segments are developing in the domestic market, and the increased awareness of food safety and quality issues is creating huge potential to catalyse a vibrant domestic market that could drive demand of quality produce. This pilot therefore targeted the lower- and middle income areas as this represents a large pool of potential consumers of safe FFV.

A notable opportunity is to tap into the link with the export FFV market. Fresh produce that complies with food safety and quality standards is in high demand not only in the export market, but also in many urban markets of Kenya. In some cases, fresh produce ready for the export market can be rechannelled to the domestic market (Gema et al., 2018). This is an opportunity to capitalize on the experiences of the export-oriented market, which already exists in Kenya, for the benefit of the domestic market.

While the challenges linked to meeting food safety and quality standards are critical in the domestic market, it is noted that the parallel Kenyan export market actors have managed to meet the very stringent standards such as GLOBALG.A.P. certification for external markets. A recent study analysed the extent to which i) there is potential to tap into existing skills, capacities and knowledge acquired for the export market and channel them to enhance safety and quality in the domestic market, and ii) there is market demand and interest that can offer opportunity to deliver FFV with safety and quality attributes (Gema et al., 2018). The findings indicated that there is a correlation between certification and compliance with good agricultural practices (GAP) (e.g. use of approved products, compliance with pre-harvest intervals and hygiene requirements, soil and water analysis) for domestic 
crops at almost the same level as export crops produced at the same farm. This confirms what other studies have found in relation to the potential for knowledge spillovers from the export subsector to elevate the domestic horticulture subsector towards quality and safety guided by standards (Mithöfer et al., 2008; Lenné and Ward, 2010).

This potential, coupled with the growing concern of consumers with food safety issues, indicates an untapped market and the need for innovative market systems development to improve quality and safety in the domestic FFV market. As part of the 3R Kenya project (https://www.3r-kenya.org) the insights gained from the survey by Gema et al. (2018) informed the idea of piloting a proof of concept to explore potential for innovating a market system to catalyse demand for traceable and verified FFV for the domestic market. The pilot aimed to generate evidence from lessons learned in the process of setting it up and to shed light on the governance issues of establishing an alternative supply chain, as well as on the types of information and data management systems needed to improve the chance of success of a market that is hinged on traceability. The initial findings and lessons learned from this pilot are presented here. 


\section{Conceptualizing the pilot}

\subsection{Aim and objectives}

The pilot aimed to test if a market can be catalysed to stimulate a local certification process as part of a new system for the domestic market. Farmers who are already supplying to the export market, and are therefore already certified, potentially serve as a pool to supply the domestic market - specifically to the market segment that is responsive to food safety concerns through traceable production, handling and trade.

The pilot concept was developed taking into account various assumptions as summarized in Figure 1. The aim was to work with early adopters to explore opportunities to integrate food safety standards in the domestic market while testing a traceability system to find a suitable tool for the marketing of FFV in Kenya (Chemeltorit et al., 2018).

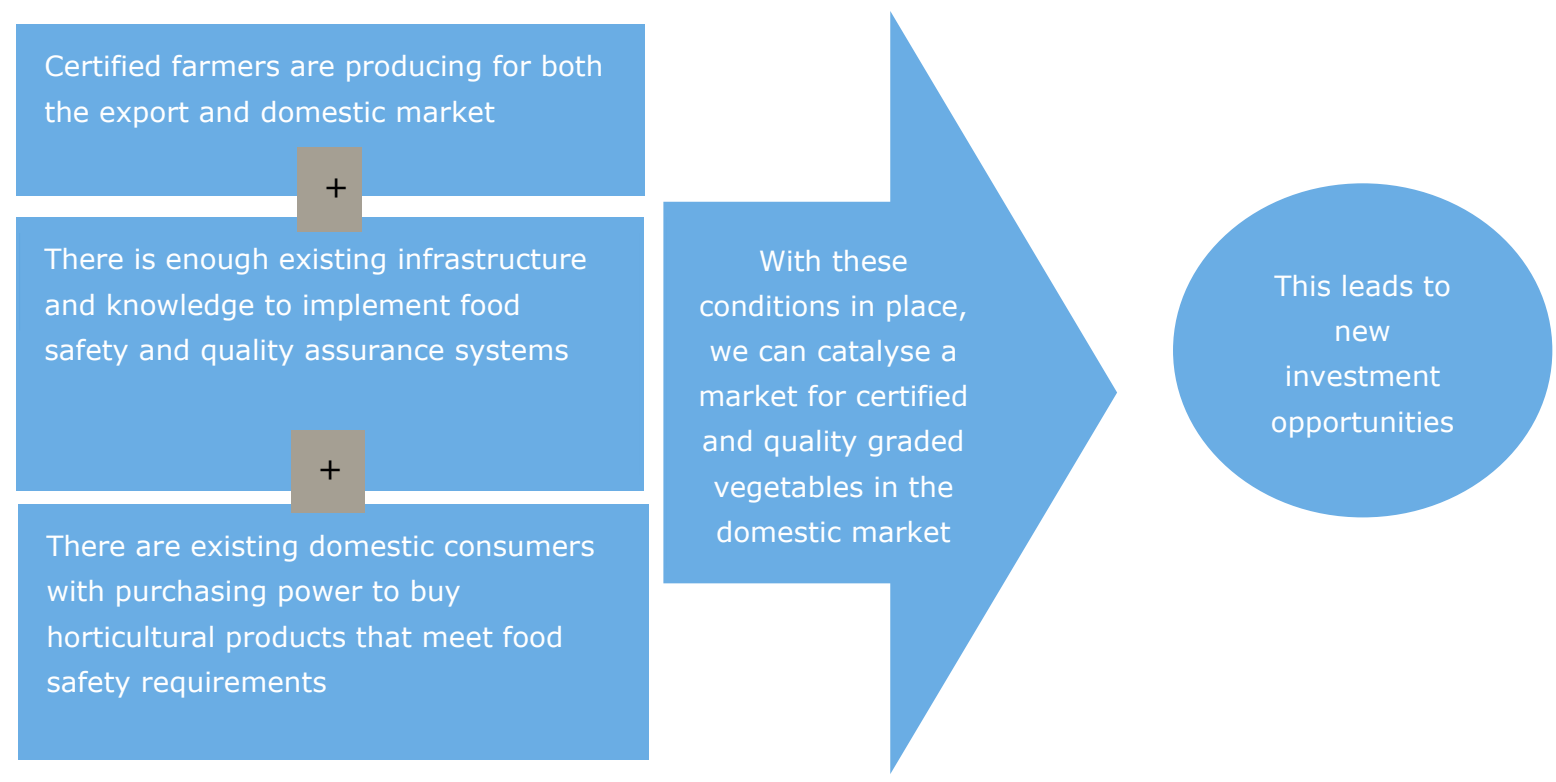

Figure 1 Summary of the assumptions underpinning the pilot concept

\section{Overall objectives}

- To validate the hypothesis that farmers who produce higher quality FFV that meet stricter food safety requirements (i.e. they are already engaging with the export market) can be linked to identified domestic market segments interested in buying the produce, as part of catalysing a market for traceable produce.

- To identify a suitable traceability system for the FFV sector in Kenya that can be used to catalyse a market for quality graded vegetables with higher levels of assurance in terms of food safety.

\section{Research questions}

- How can the supply chains for FFV be organized to stimulate the production and marketing of higher quality produce that meets stricter food safety standards?

- What are the main challenges and opportunities for farmers, transporters and grocery stores in delivering FFV that meets quality and food safety standards and that is also traceable? 


\subsection{Scope}

This action research pilot was carried out in Embu, Kirinyaga and Machakos counties, which have a large pool of farmers certified under GLOBALG.A.P. In addition, non-certified farmers from Nakuru and Kakamega counties were added to the pilot to assess whether introducing localg.a.p. certification (see Box 1) to these farmers would result in behavioural changes as well as to assess whether farmers see value for their money and can justify the cost of investment. localg.a.p. is a cost-effective solution to safety assurance for emerging markets that are unable to meet stringent standards. It acts as a stepping stone, building the capacity of suppliers to move towards attaining certification. While in Kenya it had not been introduced yet, localg.a.p. is used in other countries for a similar target group of smallholder FFV farmers, for example in South Africa. Bookmarking allows buyers information about the certificate status of registered producers.

\section{Box 1 localg.a.p. as stepping stone to achieving certification}

localg.a.p. has been designed by GLOBALG.A.P. (https://www.globalgap.org/uk_en/) to be used as a capacity-building tool or applied as a local standard for agricultural supply chains, especially in developing economies and emerging markets. It is intended to help producers adopt GAPs that can improve the efficiency of farm management, cut exposure to food safety risks and comply with food safety legislation. Through these steps, producers can gain increased access to local and regional markets. localg.a.p. is the entry level of GLOBALG.A.P.

localg.a.p. is also a key building block for producers who need GLOBALG.A.P. certification to access demanding markets. With this tool, buyers can increase their sourcing possibilities by developing a network of reliable producers that are already linked to the internationally recognized standard of GLOBALG.A.P.

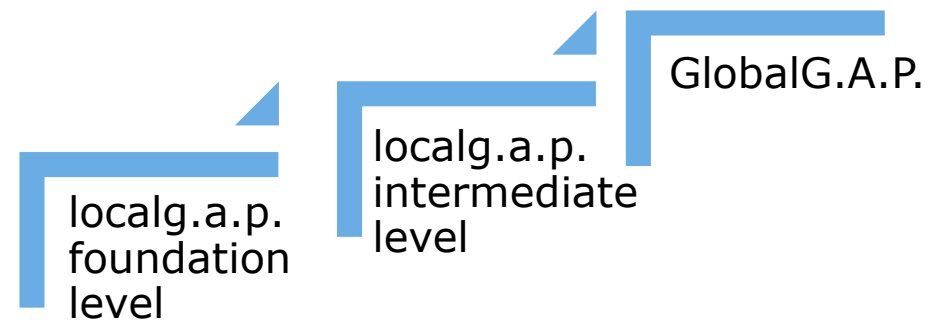

Source: https://www.globalgap.org/uk_en/for-producers/localg.a.p./

Operationalizing localg.a.p. needed to be done as a certification process. React Cert Africa (RCA) which is an independent certification division of Tradecare, was chosen to do the audit and certification of the farmers. Figure 2 shows the certification process that was followed for localg.a.p. (which follows the same certification steps as for GLOBALG.A.P. certification).
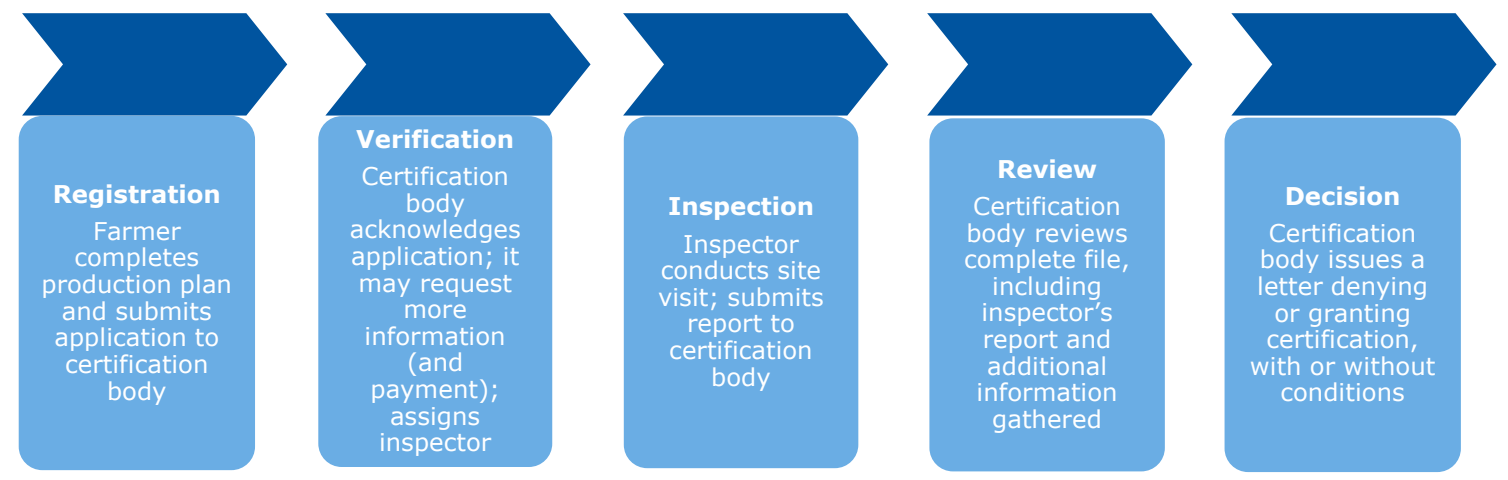

Figure 2 Certification process 
As part of being able to supply safe food a traceability system is an essential component (Figure 3). An earlier study (Chemeltorit et al., 2018) had identified the eProd system (https://www.eProdsolutions.com) as the most suitable system for the horticulture sector. Testing of the eProd traceability system was incorporated into the pilot.

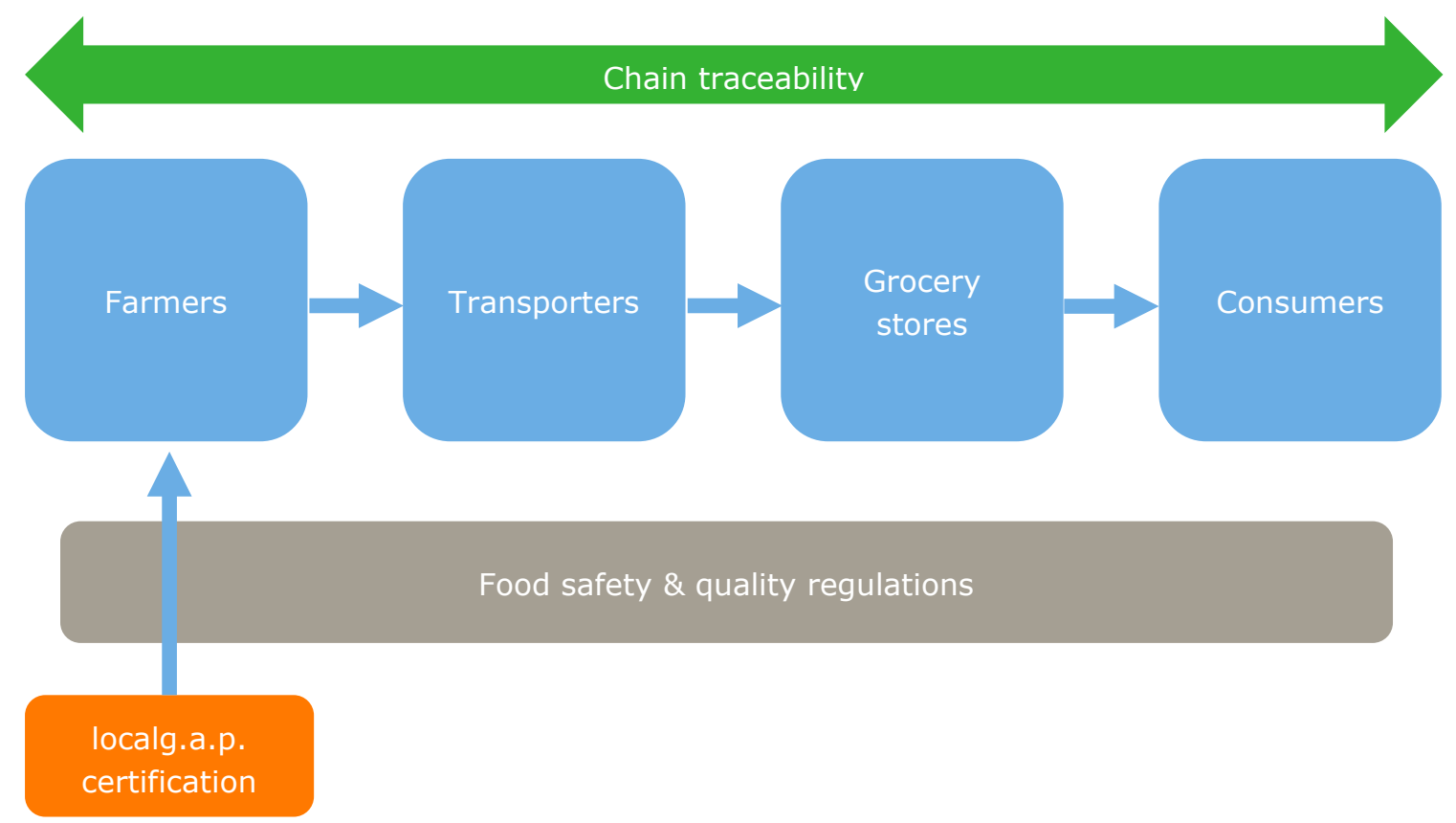

Figure $3 \quad$ Visualisation of the relationship between chain traceability and food safety \& quality regulations (adapted from Aung \& Chang, 2014)

\subsection{Methodology}

A two-step process was followed to undertake the action research study.

Step 1 was setting up the pilot. The processes to do this were documented by the team in various internal reports and documents. Several meetings were organized to reflect on these processes and to draw out the key lessons and insights from them. They were then systematically documented and are presented in section 3 of this report.

Step 2 was to review the pilot by conducting a rapid assessment through a survey to monitor the implementation of the process. The outcome of this is described in section 4 of this report.

\subsubsection{Market development}

Market development entails understanding the market demands and how to organize linkages between farmers and different interested buyers. Therefore, during the first step of the pilot, some key structural arrangements were made to contribute to these linkages, including:

1. setting up procedures and contracts to make the pilot not just a theoretical exercise, but a factual business relationship among actors

2. facilitation of dialogue between farmers and grocery stores to understand the different needs and expectations of actors in the pilot

3. training of farmers on GAP and requirements of localg.a.p.

4. providing business and technical support to farmers, so they would able to deliver the necessary quality required by grocery stores and food businesses

Stimulating a market system that seeks to offer food safety assurance as its value proposition is innovative in the domestic FFV market in Kenya. Getting it started required bringing together different business and supporting actors to co-develop the business model. To operationalize the pilot, the market system design was developed as summarized in Figure 4. 
FG1

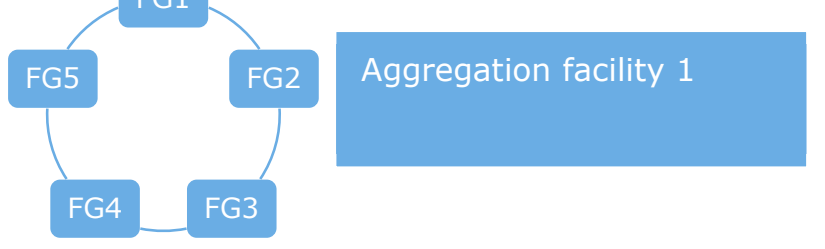

FG1

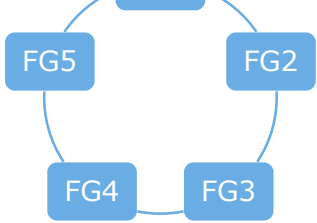

Innovative

logistical

infrastructure

(use aggregations

for markets,

transparent

Aggregation facility 2

governance)
Grocery

stores

Figure 4 Design for delivery of FFV that meet high quality and food safety standards (FG= Farmer Group)

The overall process of carrying out the pilot is summarized in Figure 5. While the initial plan was that the pilot would take six months, it actually took 18 months, from June 2018 until December 2020.

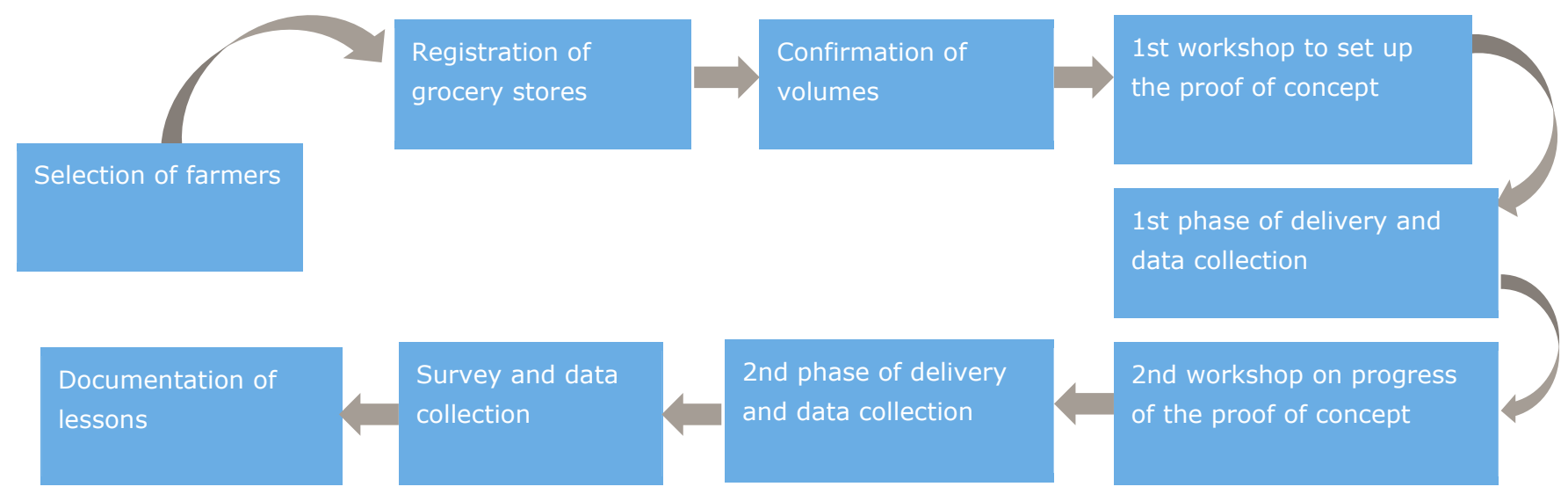

Figure 5 Road map for the pilot project

The first step for the pilot was to identify and mobilize the partners who would be interested in participating in the pilot. There were five categories of partner: farmers, transporters, grocery stores, intermediaries and the supporting actors (Table 1).

Tradecare (www.tradecareafrica.com) took on the intermediary role of bringing the different actors together. As the main actor in the pilot, Tradecare aimed to develop an innovative market system (Figure 4) as part of its broader business model. The business model included private extension service delivery offered by Mazao Safi and market development services offered by Lishe Safi; both are subsidiaries of Tradecare. 
Table 1 The value chain actors and their different roles in implementing the pilot study

\begin{tabular}{|c|c|c|c|c|}
\hline Farmers & Transporters & Grocery stores & Intermediaries & Support actors \\
\hline $\begin{array}{l}\text { - Implement } \\
\text { localg.a.p. } \\
\text { - Transparent dealing } \\
\text { - Timely } \\
\text { communication } \\
\text { - Reliable supply } \\
\text { - Maintain records }\end{array}$ & $\begin{array}{l}\text { - Transport produce } \\
\text { - Maintain hygiene } \\
\text { - Maintain reliability } \\
\text { - Facilitate } \\
\text { communication } \\
\text { - Timely } \\
\text { - Maintain records }\end{array}$ & $\begin{array}{l}\text { - Transparent pricing } \\
\text { - Timely order } \\
\text { projection } \\
\text { - Transparent dealings } \\
\text { - Timely payments } \\
\text { - Promote safety to } \\
\text { - Hygienic display } \\
\text { - Grow demand }\end{array}$ & $\begin{array}{l}\text { Trade care: } \\
\text { - Communication and } \\
\text { coordination } \\
\text { - Facilitate linkages } \\
\text { B2B and other } \\
\text { support services } \\
\text { - Develop and } \\
\text { maintain the } \\
\text { bookmark for the } \\
\text { producers } \\
\text { Mazao Safi: } \\
\text { - Extension services } \\
\text { - Support producers } \\
\text { to implement } \\
\text { localg.a.p. } \\
\text { Lishe Safi: } \\
\text { - Collect data } \\
\text { Facilitate audits }\end{array}$ & $\begin{array}{l}\text { - WCDI: Research } \\
\text { coordination } \\
\text { - County: Facilitate } \\
\text { grocers to grow } \\
\text { market } \\
\text { - Input suppliers: } \\
\text { Training and } \\
\text { capacity support } \\
\text { - Donors: Joint } \\
\text { learning } \\
\text { - Consumers: Taking } \\
\text { action }\end{array}$ \\
\hline
\end{tabular}

After actors were identified, grocery stores were registered and an assessment of their volume and quality needs was carried out. The quality, volumes and other trading requirements were validated in a workshop with farmers and grocers. The quality, trading requirements, product specifications (see Appendix 1) and volumes (see Appendix 2) were validated in a workshop with farmers and grocers.

\section{CERTIFIED, TESTED \& TRACEABLE FRESH FRUITS \& VEGETABLES}

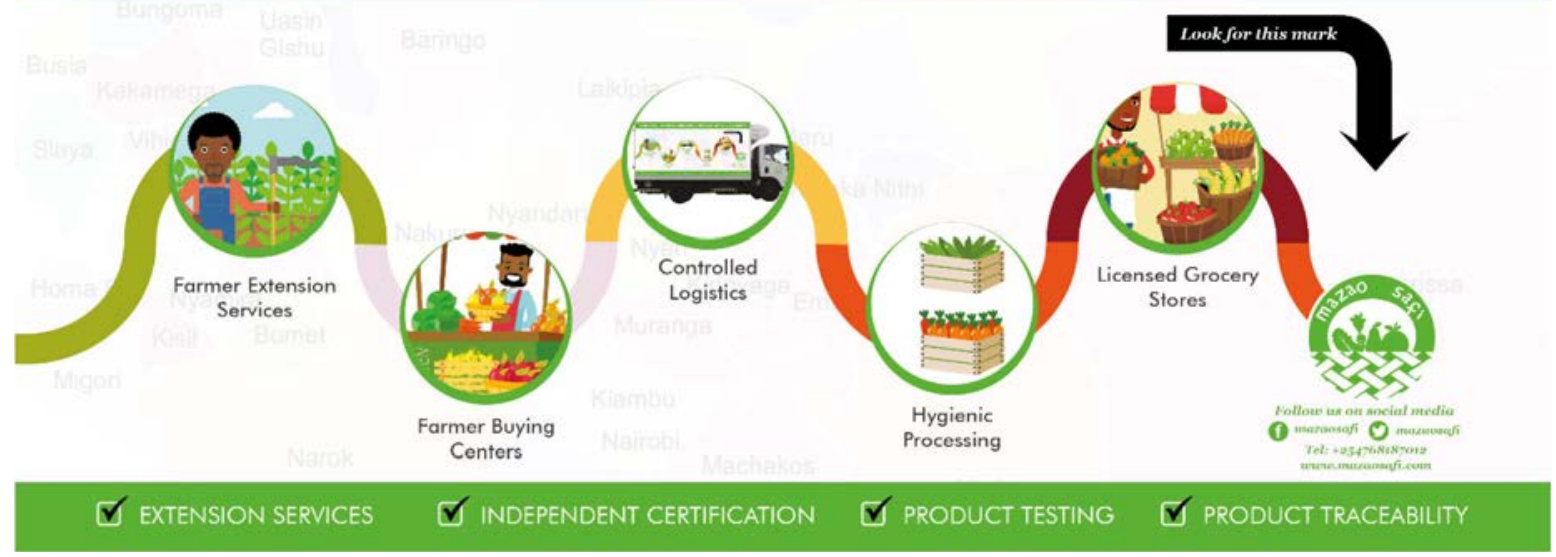

Figure 6 A graphic of the marketing system as envisaged by Tradecare

\subsubsection{Monitoring of the pilot}

A survey (December 2019 - January 2020) was carried by staff of Jomo Kenyatta University of Agriculture and Technology (JKUAT) who were not part of the implementing team. The purpose of the survey was to learn from the setting up of the pilot, the potential bottlenecks, lessons learned and opportunities to scale the pilot concept.

The study population consisted of farmers, transporters, grocers and consumers in Nairobi, Embu and Kirinyaga counties (see Table 2). In Nairobi, the survey targeted transporters, grocer and consumers, while in Embu and Kirinyaga it targeted farmers from the group who were already certified under GLOBALG.A.P. 
Table 2 Number and type of value chain actors interviewed as part of the survey

\begin{tabular}{|c|c|c|c|c|}
\hline County & & Respondents & Male & Female \\
\hline \multirow[t]{2}{*}{ Nairobi } & Transporter & 2 & 2 & - \\
\hline & Grocery store keeper & 45 & 6 & 39 \\
\hline Embu & Farmer & 41 & 32 & 9 \\
\hline Kirinyaga & Farmer & 30 & 23 & 7 \\
\hline
\end{tabular}

The key informant interview guide consisted of both structured and open-ended questions with a focus on information that affects the quality and food safety of FFV (see Appendix 3). Based on the information obtained, the strong points, opportunities for improvement, risks and suggestions for improvement by the various actors along the value chain were derived. 


\title{
3 Establishing demand, production and market linkages
}

\subsection{Identifying and enlisting potential actors}

\begin{abstract}
Farmers
The pilot was guided by the assumption that there was a pool of farmers who were producing for both export and domestic markets following almost similar practices. This was confirmed by a previous survey (Gema et al., 2018). Two hundred farmers from Embu, Kirinyaga and Machakos counties who were already GLOBALG.A.P. certified were identified; Tradecare was able to get information about these farmers through GLOBALG.A.P. In addition, through exploratory visits and contacts made with other potential partners, they identified a second group of 35 non-certified farmers from Nakuru and Kakamega counties. Over 200 farmers represented by 12 farmer groups were selected with a weekly trade volume of approximately 68 MT of mixed FFV.
\end{abstract}

\section{Transporters}

Transporters were not an easy group to enrol in the pilot. Tradecare supplied one truck, and two commercial transporters were hired to transport the produce.

\section{Grocery stores}

Sixty grocery stores were identified as potential market outlets to engage in the pilot. Selection of grocery stores for participation was based on their interest in direct sourcing and in offering food safety assurance products but also other criteria as summarized in Table 3 . The grocery stores were distributed in different localities in Nairobi County (Figure 7). About 57\% (34) were owned by males compared to about $43 \%$ by females. The selected stores were characterized by a reasonable level of investment in the business (i.e. with semi-permanent or permanent infrastructure) (Figure 8).

Table 3 Criteria for the selection of grocery stores for the pilot

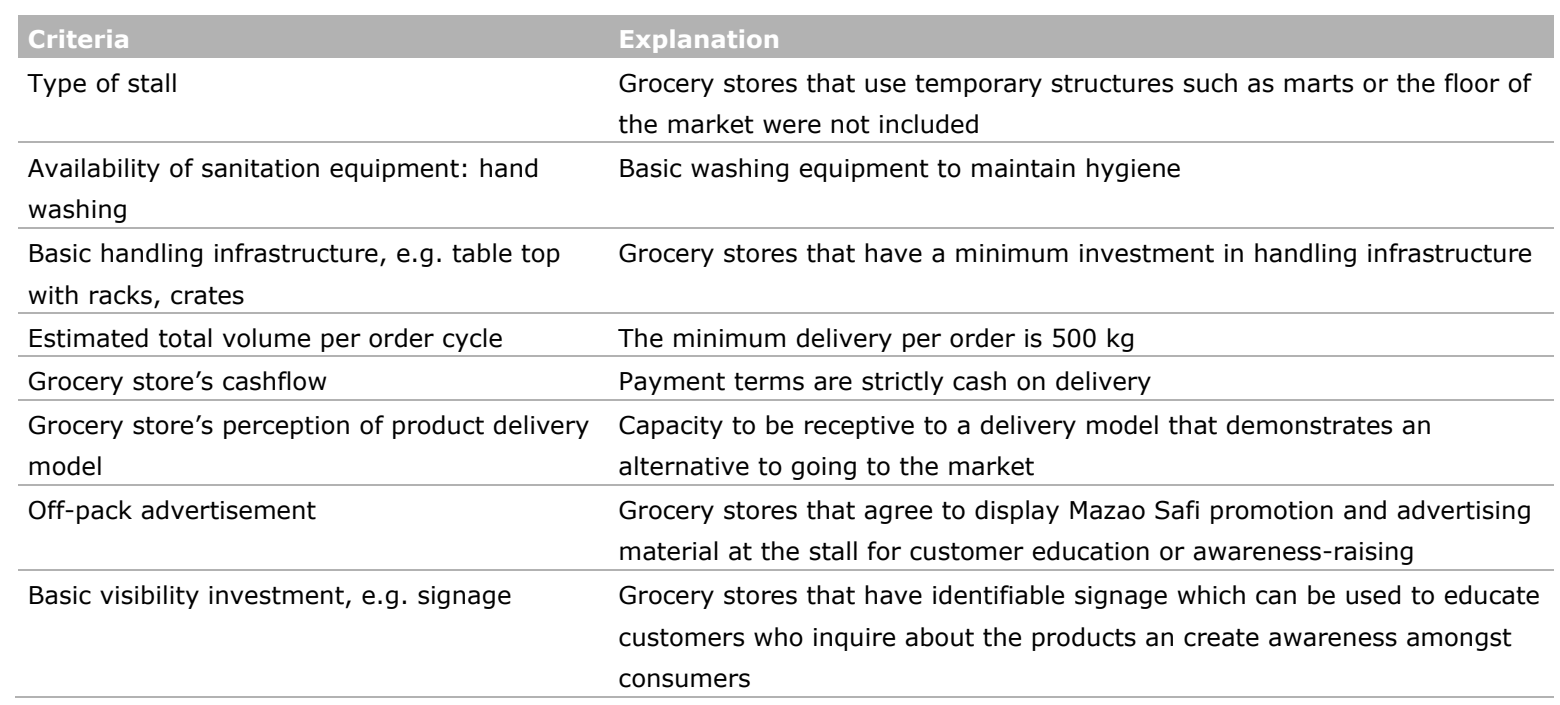




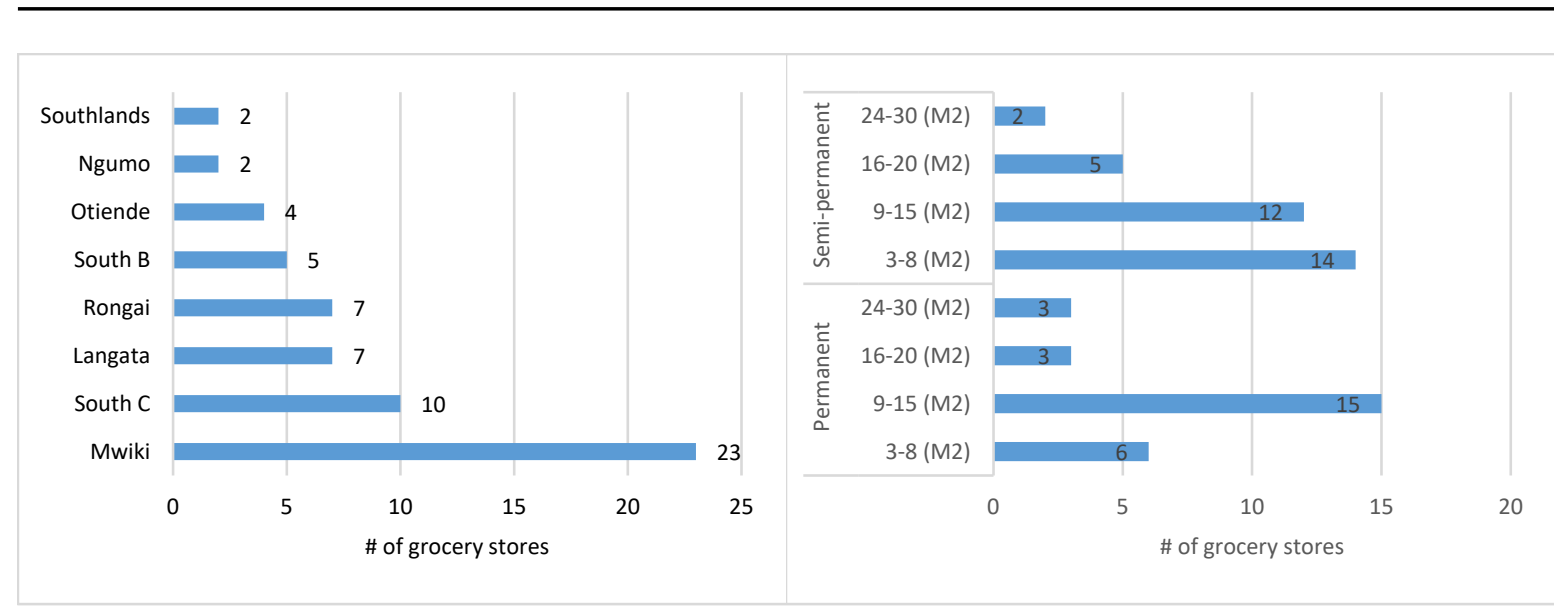

Figure $7 \quad$ Location of grocery stores

Figure $8 \quad$ Type of stalls and size

After potential farmers and grocers were identified, a workshop was organized with a select number of these actors, who came together to deliberate on the pilot. The consultation with grocers identified the need to work with a huge variety of products but also with diverse specifications. In total, $37 \mathrm{FFV}$ products were identified:

Vegetables: potato, tomato, bulb onion, cabbage, spinach, kale, amaranth, African night shade (commonly referred to as managu), spider plant (commonly referred to as mgagani/thageti/nsaga), sweet potato, carrot, capsicum, garlic, ginger, garden pea, yam, pumpkin, cucumber, leek, arrowroot, cow pea and spring onion.

Fruit: banana (ripe), avocado, watermelon, oranges, yellow passionfruit, pineapple, mango, tree tomato, thorn melon, green banana, pear, pawpaw, parsley, plum and local passionfruit.

The dialogue with grocers and farmers provided guidance on product specification to ensure quality. The details of the product specifications are given in Appendix 1.

\subsection{Developing product prototypes}

Since there are no standardized grades in the domestic FFV market, the pilot developed prototypes of each product with standardized units of measurement that were agreeable to grocers. This meant that farmers in the pilot would sell produce in standardized packs with labelling and identification of the product origin.

The prototypes were based on the product form and weight and the packaging to be used. Crates were the most common packs for both vegetables and fruit (Figures 9a and 9b), and shredding was the least common, with only spinach and cabbage sold in shredded packs.

The crates, nets, bunches and shredded products come in different sizes depending on the type of FFV (Figures 10a and 10b). The biggest crates used were $60 \mathrm{~kg}$, and they were mostly for fruit. Crates of $30 \mathrm{~kg}$ were the most common pack for vegetables. Nets were also a common form of packaging, with $1 \mathrm{~kg}$ packs used for $46 \%$ of all vegetables packed in nets and $15 \mathrm{~kg}$ packs used for $92 \%$ of the fruit packed in nets. 


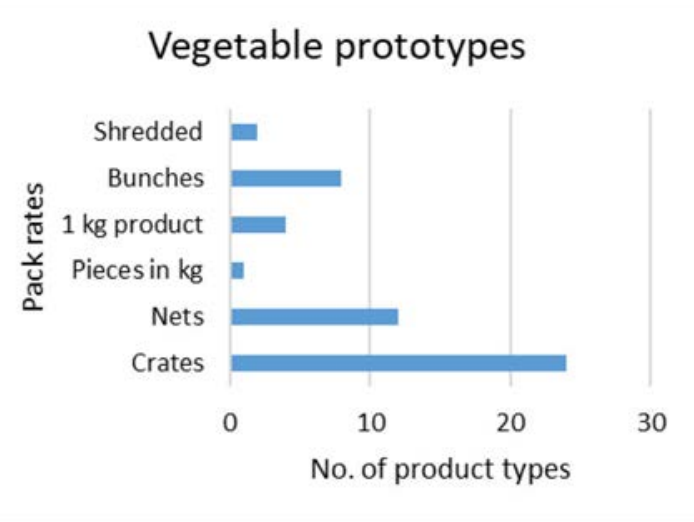

Figure 9a Vegetable packaging prototypes

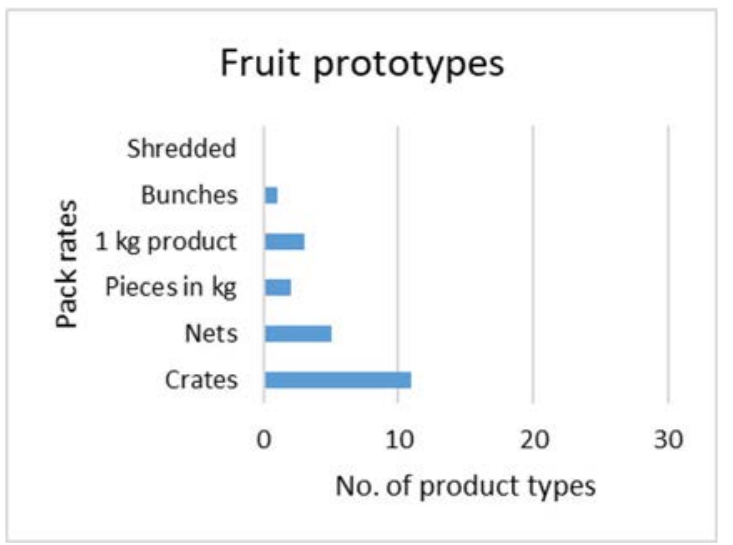

Figure $9 \boldsymbol{b} \quad$ Fruit packaging prototypes

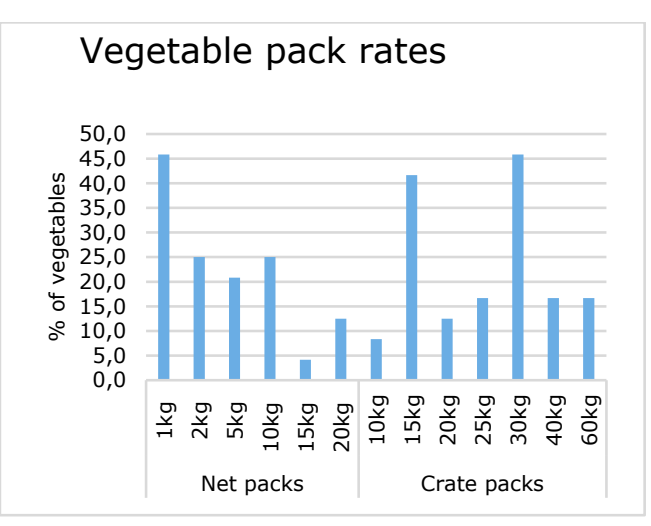

Figure 10a Net and crate pack weights for vegetables

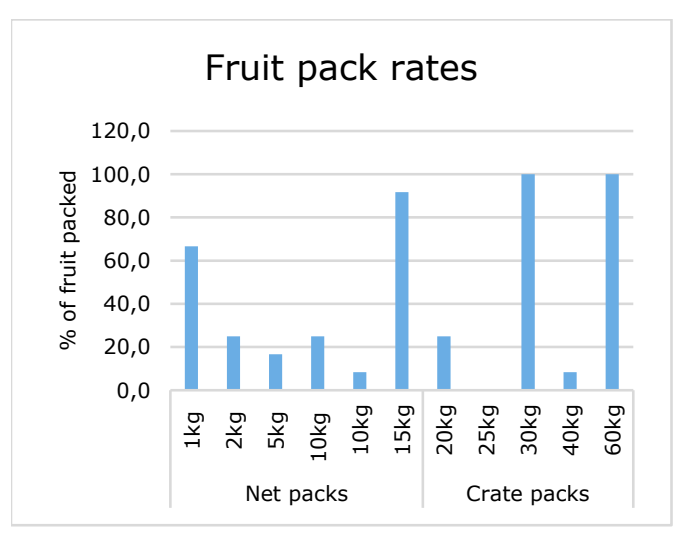

Figure 10b Net and crate pack weights for fruit

\subsection{Setting prices and volume projections}

The approach to forecasting volumes needed to supply the markets was based on worst, most likely and best case scenarios for Embu, Kirinyaga and Machakos hubs as follows (see Appendix 2):

- Worst case scenario - These projections are based on factors such as poor agronomic practices, natural and human-caused disasters and pest and disease prevalence.

- Most likely scenario - These projections are based on production of the given product for the specific region and individual farmers' estimated productivity.

- Best case scenario - These projections are based on scenarios where farmers follow extension workers' advice (on compliance to localg.a.p. standards) and apply good agronomic practices, no natural and human-caused disasters and low pest and disease prevalence.

For all hubs, total volume of FFV for the most likely scenario was double the total volume for the worst case scenario, and the best case scenario was $25 \%$ more than the most likely scenario. Large, medium and small grocery stores would expect average weekly demand of $41,300 \mathrm{~kg}, 26,800 \mathrm{~kg}$ and $15,860 \mathrm{~kg}$ of FFV respectively, giving a potential demand of $83,960 \mathrm{~kg}$ as the baseline.

With regard to price setting, the following factors were taken into account: certification costs for localg.a.p., transportation from the farms to the packing facilities, and costs of packing material and delivery. Furthermore, a total of $18 \mathrm{KES} / \mathrm{kg}$ was included for the technical advice given by Mazao Safi. Prices were benchmarked against the buying and selling prices on the wholesale wet markets. Mazao Safi provided a $20 \%$ (premium) on the wholesale price to encourage farmers to participate in the pilot; this price is much higher than they would receive outside the pilot. 


\subsection{Promoting viable production models and suitable service delivery models to ensure traceable products}

To match market demand for quality and safe produce (the value proposition of the pilot / innovative market), farmers were expected to use certain practices, implement procedures and follow a production schedule to ensure consistent, timely and quality production and traceability.

\section{Training}

Within the pilot, farmers were trained in the requirements of localg.a.p. and supported to implement traceability of their products. This was done through provision of crop calendars (Figure 11) with approved materials, and support in record-keeping and appropriate harvesting procedures. In group discussions at workshops, grocers reiterated the importance of traceability and were ready to work with farmers on implementing it.

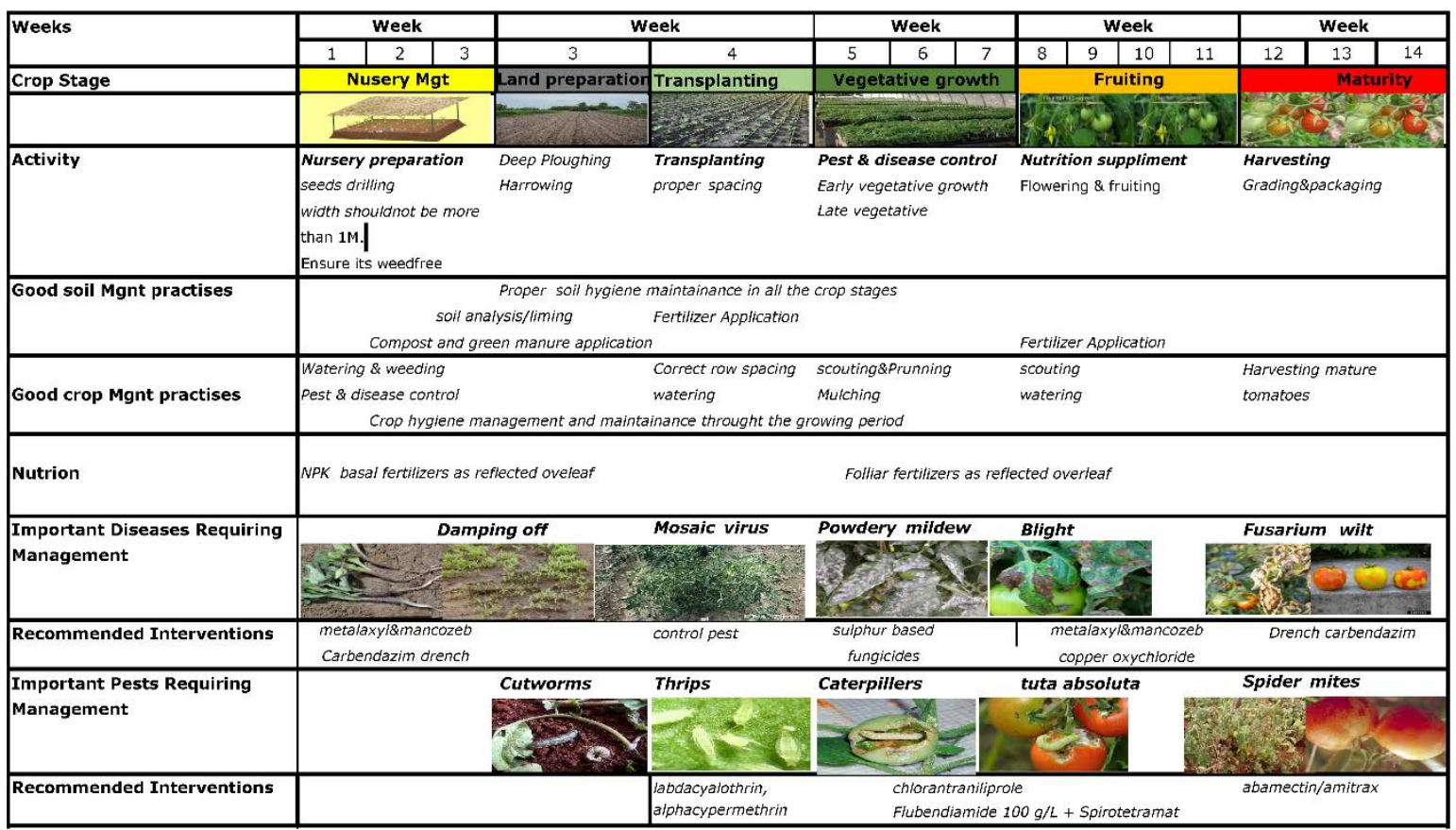

Figure 11 Example of a crop calendar for tomato

To complement the guidelines and crop calendars, technical fact sheets were developed in partnership with companies such as Koppert, which provides sustainable solutions for pest control. Technical advice for farmers was key to ensuring products offered to market were of good quality at each step from production to harvest by helping them with the steps of:

- managing quality at farm level

- complying with maturity indices

- following recommended modes of harvesting

- grading of produce

- storing produce on the farm

- handling post-harvest losses

- packaging, both wholesale and retail, and transportation.

\section{Standards}

In order to ensure a stepwise involvement in the pilot, localg.a.p. was found to be suitable to guarantee quick adoption by farmers (Table 4). 


\section{Table 4 Benefits of localg.a.p. to different actors}

Farmers

The localg.a.p. programme reduces exposure to food safety risks as the farmer complies with food safety and proper hygiene requirements and legislation

It improves efficiency of a farmer's farm management

Relevant documents are accessible online, free of charge

The localg.a.p. number, a unique 13-digit code that identifies the farmer in the database, assures buyers and improves farmers' traceability

It provides access to local and regional markets through a local programme based on a globally recognized certification system

It enables farmers to follow a stepwise improvement plan towards acquiring certification, should they wish to

localg.a.p. reduces exposure to food safety risks as farmers comply with food safety and proper hygiene requirements and legislation
Retail markets and grocery stores

localg.a.p. provides a stepwise improvement plan for food safety and sustainability, improving the quality of the food supply to consumers

It is an integrity programme in the sense that it assures certification reliability and high auditing performance

It provides a network of reliable retailers, hence assuring the market for produce

Farmers' reports can be inspected through the database using the localg.a.p. number, hence improving traceability

It assures grocery stores that the goods being produced comply with the food quality and safety requirements localg.a.p. creates an opportunity for grocery stores and retailers to source local and regional products that meet the localg.a.p. food safety and hygiene requirements

It was expected that the cost of certification would be absorbed by farmers, but this assumed that farmers could make such an investment without an analysis of the costs, risks and benefits. Table 5 shows the costs of certification for new individual farmers and for farmers already certified under GLOBALG.A.P. It illustrates that the cost for farmers seeking to add on localg.a.p. to their existing GLOBALG.A.P. is about half the cost of beginning with localg.a.p.

Table 5 Costs for localg.a.p. certification on individual farmer basis

\begin{tabular}{|c|c|c|}
\hline Cost line & $\begin{array}{l}\text { cost in KES* of } \\
\text { localg.a.p. } \\
\text { certification }\end{array}$ & $\begin{array}{l}\text { cost in KES of localg.a.p. } \\
\text { certification if already certified } \\
\text { under GLOBALG.A.P. }\end{array}$ \\
\hline Testing and calibration & 36,000 & 0 \\
\hline Certification/verification body (RCA) costs & 54,000 & 54,000 \\
\hline TOTAL & 116,400 & 56,400 \\
\hline
\end{tabular}

* At the time of the study, 2019, the exchange rate was 1 euro was equivalent to 116 KES

Further analysis shows that acquiring the localg.a.p. certification is cheaper for famers in a group (Table 6), with larger farmer groups (around 100 members) being able to take advantage of reduced costs compared to smaller groups (around 25 members). The difference is about $42 \%$.

Table 6 localg.a.p. certification costs per farmer group

\begin{tabular}{lrr} 
Cost line & $\begin{array}{c}\text { cost in KES for } \\
\text { group of } 25 \text { farmers* }\end{array}$ & $\begin{array}{c}\text { costs in KES for } \\
\text { group of } 100 \text { farmers** }\end{array}$ \\
Documentation & 60,000 & 60,000 \\
\hline Testing and calibration & 90,000 & 120,000 \\
\hline Certification/verification body (RCA) costs & 180,000 & 360,000 \\
\hline Registration fee & 12,720 & 50,880 \\
\hline Cost of uploading farmer information into database & 18,600 & 27,600 \\
\hline TOTAL & $\mathbf{3 6 1 , 3 2 0}$ & $\mathbf{6 1 8 , 4 8 0}$
\end{tabular}

* 25 farmers per farmer group - small to medium scale; approx. 2-5 acres

** 100 farmers per farmer group - very small scale; approx. 1 acre 
By targeting 5,000,000 kg, grocery stores were spending less money per $\mathrm{kg}$ sourcing from multiple farmer groups with 100 members (around KES $1.43 / \mathrm{kg}$ ) than when sourcing from a single group with 100 members (KES 2.47/kg; Table 7). However, sourcing from 20 groups with 25 farmers each (at KES $1.85 / \mathrm{kg}$ ) became more expensive than sourcing from one group with 25 farmers (KES 1.44/kg). Working with 20 groups with 100 members was more cost effective than smaller groups of 25 members per group. Expanding the scope of the pilot from the original 12 farmer groups with additional groups (i.e. 20 groups from five regions; 4 groups per region) was economically more advantageous.

Table $7 \quad$ localg.a.p. costs on multiple farmer groups basis

\begin{tabular}{|c|c|c|}
\hline Cost line & $\begin{array}{l}\text { cost in KES if sourcing from } \\
20 \text { groups of } 25 \text { farmers }\end{array}$ & $\begin{array}{l}\text { costs in KES if sourcing from } \\
20 \text { groups of } 100 \text { farmers }\end{array}$ \\
\hline Auditor fees & 30,000 & 60,000 \\
\hline Group costs & 181,320 & 258,480 \\
\hline Total costs per group & 231,320 & 358,480 \\
\hline Kgs of produce & 5,000 & 2,500 \\
\hline Costs per kg produce & 1.85 & 1.43 \\
\hline
\end{tabular}

As the cost of checking for maximum residue levels was in most cases prohibitive for farmers, COLEACP provided additional support for this. Samples were collected from farmers and sent to the KEPHIS laboratories for analysis. However, the delay in processing the samples meant that these results could not be included in this report.

Labelling and product identification

To distinguish the produce that was part of this pilot, it was labelled clearly following the principle described in Ogweni (2019) that a logo used on products should register quickly in the minds of customers. Several types of labelling and product identification modalities were tested; Figure 12 shows the design that was used in the pilot.

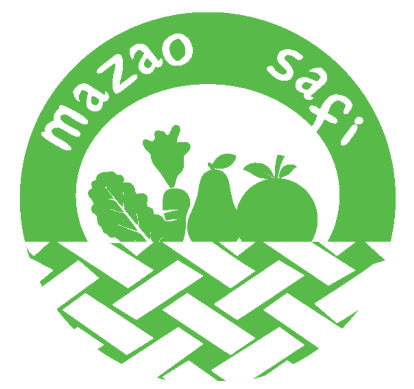

Figure 12 The logo used for labelling produce in the pilot

\section{Traceability}

During the implementation of the pilot it became apparent that eProd, although identified as the most appropriate traceability system to use in the pilot, did not satisfy to the full extent the needs of the FFV sector. This was mainly because farmers produce different crops, sometimes even in the same field. The system could not register this adequately for the purposes of the pilot, and implementation of the eProd system was not further pursued. Traceability was done manually through numbering of crates and the use of stickers on the other types of packaging (Figure 13). The numbering applied was through assigning the localg.a.p. number to the produce. 


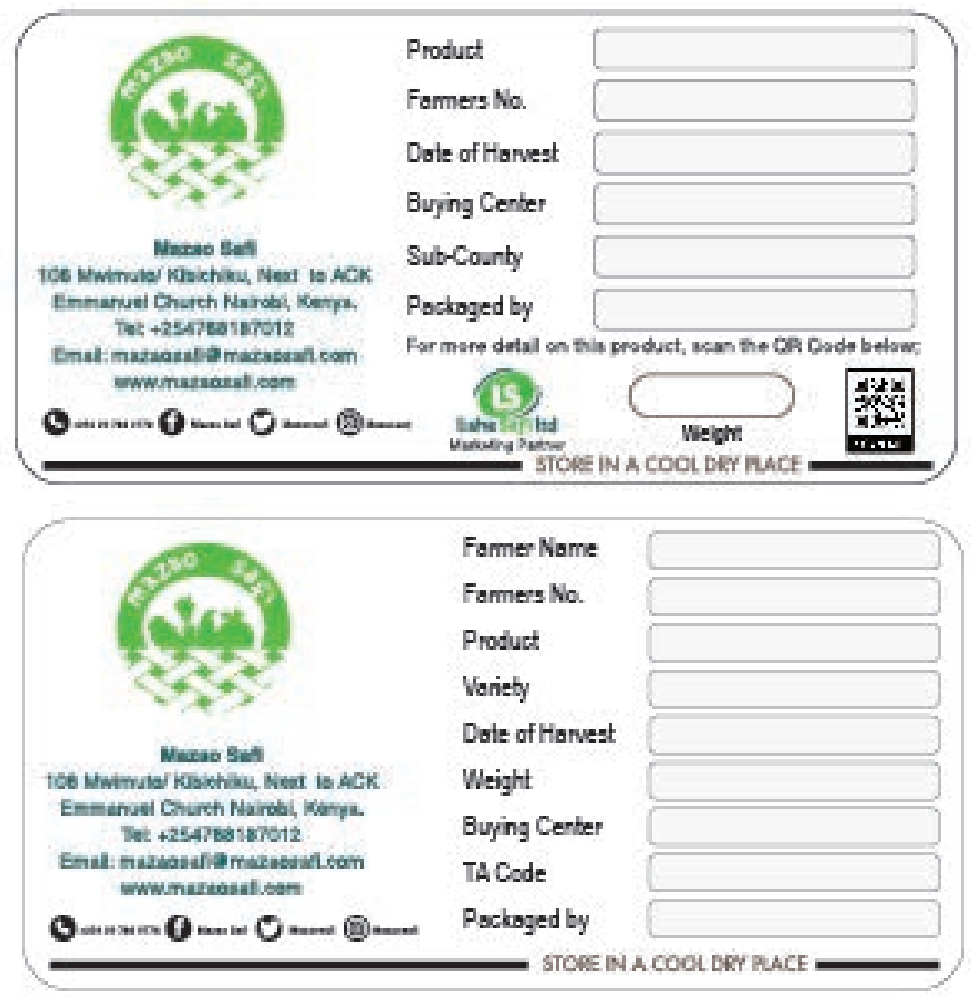

Figure 13 Example of labels applied for traceability
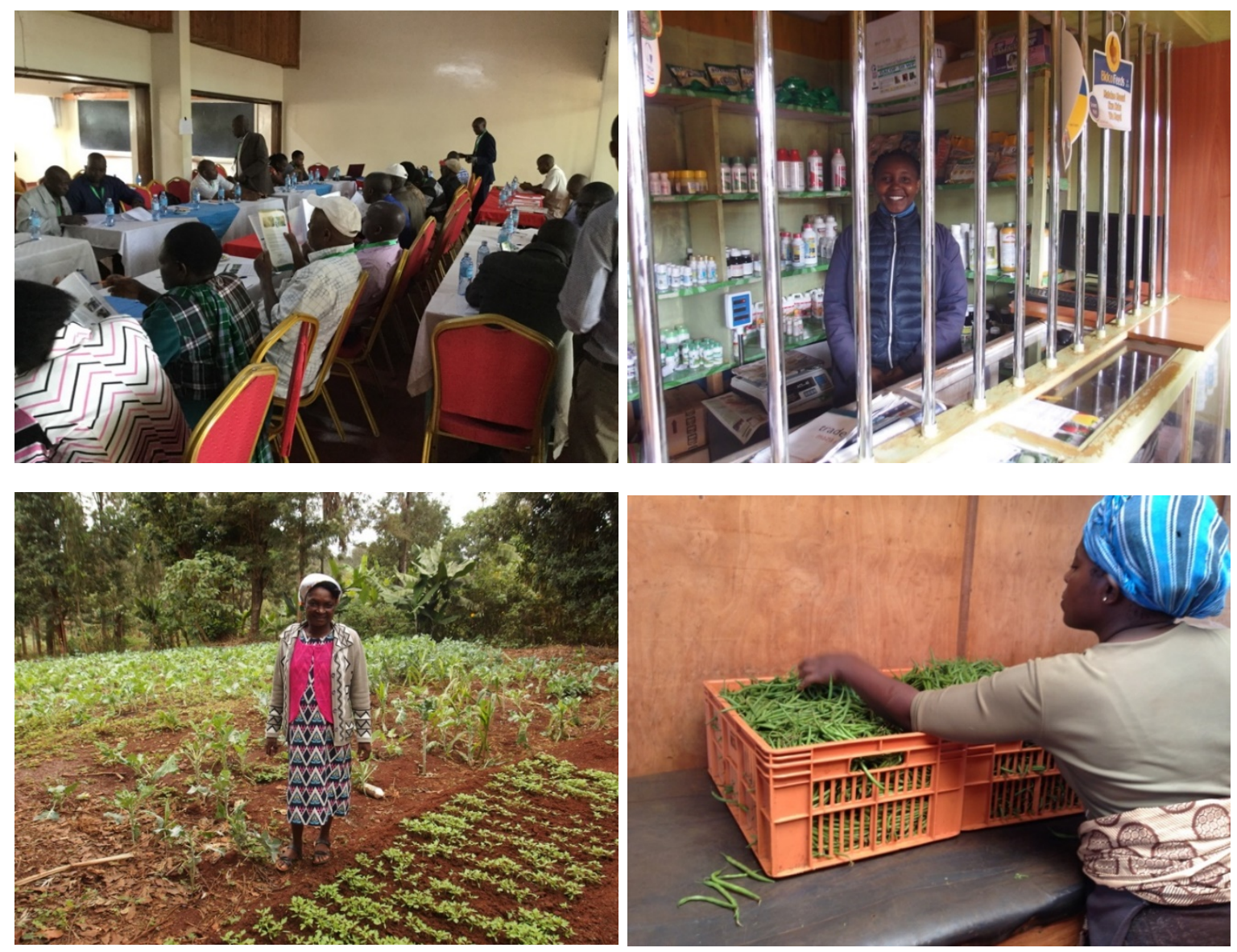

Figure 14 Photos from the pilot: Workshop with pilot participants to validate the assumptions (top left); Mazao Safi agrodealer (top right); participating farmer showing her seedlings (bottom left); and grading of produce (bottom right). 


\section{Survey}

This section presents the finding of the independent monitoring survey. The findings have been supplemented with observations made during visits to the field and the various premises.

A number of actors and activities were involved in the delivery of the produce, including farmers, transporters, pack house managers, grocery stores and consumers. All these actors have potential to influence the quality and safety of the produce; therefore, any lesson learned from the implementation of the pilot can offer important insights to future initiatives targeting better assurance models for traceability of FFV in Kenya. The strong points of the pilot as well as the challenges are reflected below for each actor, categorized per topic.

\subsection{Farmers}

Farmers were asked to reflect on the strong points and challenges for the following topics in relation to the pilot:

1. Seed source and selection

2. Soil management

3. Soil and water testing

4. Irrigation

5. Pest and disease control

6. Pesticide container management

7. Farm hygiene

8. Post-harvest handling

9. Marketing

10. localg.a.p.

11. Information literacy

\subsubsection{Seed source and selection}

Most farmers recognized the importance of quality when sourcing seed. They were able to send codes on the packaging material to confirm if the seeds are certified as good quality. They sourced good quality seeds from recognized companies; for example, tomato "Kilele" from Syngenta was known to be a high yielding variety.

Farmers were also able to collect their own seeds after harvesting the main product, for example for thorn melon. Some farmers maintained quality seeds over generations of, for example, Kikuyu indigenous maize seedling, which they believe is the sweetest maize variety.

Farmers faced several challenges. Some seeds had less than 50\% germination rate, and there was a loss of vigour in the seeds after successive generational planting. The seeds were of low quality, which increased the risk of transfer of pests and diseases. Some varieties of crops have a short shelf life; these are preferred by the farmers but not by grocers and consumers, due to their perishability. Farmers also had difficulties in accessing hybrid seeds.

\subsubsection{Soil management}

Farmers recognized the need to for proper soil management. Inorganic fertilizers were used, such as diammonium phosphate (DAP), which was applied at planting, and calcium ammonium nitrate (CAN), used for top dressing. One tomato farmer reported applying DAP as well as nitrogen/phosphorus/potassium (NPK) from Mavuno and YaraMila WINNER and YaraMila POWER at intervals of one week to hasten growth. Urea was used in small quantities due to its acidity, and lime 
was applied after three seasons to reduce the acidity of soil. Organic fertilizers were also used, such as RUE, which is a foliar fertilizer, and Mavuno, which does well on tomatoes.

Compost manure was applied; however, there was not enough manure and farmers had to buy supplies. Valuable compounds in the available compost may have leached out due to open air composting. Farmers in Embu West use leaves to speed up the efficient composting of manure. While the small plots of land discourage efficient crop rotation, it is a cultural practice and is used to improve soil quality; most farmers across Embu and Kirinyaga seem to have perfected the art. Weeds were controlled to ensure that the crops get maximum nutrients.

It was noted that knowledge about liming requirement was inadequate, so lime may be applied although it is not needed. There was also indiscriminate application of chemicals in the soil without soil testing. There was no standard measurement of fertilizer, and it was applied mainly by approximation.

\subsubsection{Soil and water testing}

Farmers were willing to do tests for soil nutrients, diseases and water quality if these services were provided, but there were many challenges. There was a lack of water-testing facilities, and most farmers had never even heard that irrigation water could be tested. There was little information on water quality from the community projects managing irrigation water. Soil-testing services were unavailable within nearby facilities, so although some farmers were willing to pay for the service they could not actually carry out any tests. Soil testing is also considered expensive.

\subsubsection{Irrigation}

The counties where the pilot took place have a good climate generally, with sufficient rains that ensure water supply year-round. However, farmers still expressed willingness to adopt irrigation practices and water harvesting. Electricity is available to pump water from boreholes, and water is available from rivers and irrigation projects from Mt Kenya, such as the GIDA project. Water pans are also used to store water; for instance, a farmer in Embu had two water pans that were very useful during dry season. Techniques such as planting tomato plants in furrows facilitate irrigation. Irrigation methods used include hose pipes and sprinklers.

Due to climate change, farmers are now less able to plan their production cycles. This can affect plant health, such as changed rain patterns that now might expose plants to disease when soil splashes on leaves.

\subsubsection{Pest and disease control}

Some pests caused total loss to the farmer. For example, when Tuta absoluta (tomato leafminer) was first noticed, farmers in Embu and Kirinyaga lost all their tomato plants and had to stop planting tomatoes for some time, even after applying all the pesticides that were then available.

In general, farmers do use pesticides but are aware of issues such as development of resistance due to excessive pesticide use. They followed instructions on the rates and interval periods of application. Some pesticides used included Topnet (active ingredient (a.i.) thiophanate-methyl) and Escort (a.i. emamectin benzoate) to control fall armyworm in maize, Dynamec (a.i. abmectin) to control thrips and flies in tomato and Absolute (a.i. azoxystrobin, difenoconazole and hexaconazole) to control powdery mildew. Farmers received recommendations from an agricultural officer on which products to use for which problems, but there were not many such officers to guide farmers on pest and disease control. Adherence to the recommendations of using specific pesticides for specific crops was weak, with farmers using multiple pesticides because they were not sure which one would work. No pesticide rotation was applied.

Non-chemical methods used to control pests and diseases included bio-nematicides, trap crops (e.g. sorghum to control pests on pumpkins) and traps to control melon flies. However, farmers rarely used biopesticides or traps, as awareness of them was low. 
Farmers were aware of the need to use protective gear such as masks, gumboots and overalls during pesticide application but not all farmers had this equipment available. Some farmers did not think that going back to the farm after spraying was a risk; on the contrary, some farmers go back immediately to check if the chemical has worked.

\subsubsection{Pesticide container disposal}

Pesticide containers were disposed of in various ways. Some farmers put the containers in a sack and buried them to prevent children from accessing them. They perforated the containers to avoid them being reused. Other farmers preferred to throw them in a pit latrine or somewhere else on the farm. Some farmers burn pesticide containers, which is harmful to the farmer and to the environment.

\subsubsection{Farm hygiene}

Field hygiene was observed during the study, such as the presence of water for hand washing. Farmers also cleaned tools to prevent contamination and spread of diseases between plants. For example, farmers in Embu used methylated spirit to disinfect the knife between plants during pruning of passionfruit, and tools were disinfected with sodium hypochlorite before harvesting bananas to prevent spread of disease from one farm to another. Clean planting materials (certified seeds) were also used. No training was provided on different hygiene practices.

\subsubsection{Post-harvest handling}

Several measures were undertaken to ensure safety. Farmers followed recommendations on pesticide labels about what pre-harvest interval to apply for different crops. Some products, such as spinach, were washed after harvest before being taken to the market. However, most produce was not washed, despite the visible need for cleaning.

\subsubsection{Marketing}

A number of marketing challenges were faced by the farmers in the pilot. Companies sometimes offered contract farmers very low prices. There were also differences in the cost of production within different regions, so farmers in areas where this was high - such as Embu - felt a disadvantage. Despite these challenges, farmers were still willing to do contractual farming.

There was also inconsistency in market prices. While some individuals and even companies were willing to buy produce at the farm gate, the prices farmers received were very low, sometimes not even sufficient to cover the cost of the harvesting labour. In those instances, farmers then prefer to feed animals with the produce.

Some seed sellers exchanged seeds for ripe product, but others took advantage of farmers as the value of the exchange is generally lower than the market value of the produce.

\subsubsection{0 localg.a.p. implementation/training and technical support}

Farmers are generally willing and ready to adopt localg.a.p. by changing their practices and producing crops under the recommended regulations. They are also willing to follow technical advice they are given. On the whole, they are willing to pay for extension services as long as it increases their production, but others believe that government should employ extension officers. Extension costs have a wide range, starting at KES 200 and reaching KES 1000. However, farmers are unwilling to pay for costs associated with certification.

Some farmers do not care about traceability as long as they make profits. They consider education to be expensive. Small-scale farmers have no training on what is expected of them to comply to food safety standards at farm level. 


\subsubsection{Information literacy}

Most farmers had attained at least basic education and could read and write. The farmers were willing and able to learn and take recommendation from other farmers and to learn from experience about what works best. Farmers followed instructions on pesticide containers about application rates, and chemical vendors also had further information that farmers could use. Agronomists also provided recommendations to farmers about different types of fertilizers and plant control products to use, but farmers found it difficult to pay for agronomist services.

Farmers believed that as long as the yields are good then records are not important; they often have no records at all about the different farm activities they are doing or the products they are using. Most farmers could not remember the fertilizers, pesticides or bio-nematicides they had used or could use to control soil disease. This lack of training in the importance of records is further challenged by the lack of support; while knowledgeable extension officers and agronomists were available, there are not enough of them and they are not well paid. The turnover of them is high as they resign when they get better opportunities elsewhere. This was the case with the extension officer in Kirinyaga, who was new at the time of the pilot as the previous two had left to pursue better opportunities.

\subsection{Transport}

Transporters were asked to reflect on the strong points and challenges for the following topics in relation to the pilot:

1. Collection

2. Loading, offloading and packaging

3. Transfer and delivery

4. Handling facilities and hygiene

5. Record-keeping

6. Communication, marketing and customer care.

\subsubsection{Collection}

The basic process of getting produce from the farm to the shops begins with pick-up from farms. Drivers, with the help of field extension officers and marketing officers, were able to pick up tomatoes and onions from Loitoktok and take them to grocers around the Nairobi area. The drivers already knew where produce was ready to be picked up. When products arrived from the field, they were divided and placed in different crates according to maturity, type and size. However, a number of issues and challenges were described as part of the collection process.

Inadequate quality checks on produce: On arrival at the pack house, it was discovered that some tomatoes and onions were rotten; this indicates that they were already of poor quality during farm picking and should have been discarded at that stage of the process. Some watermelons picked from farms were not ripe, being a pale white colour instead of characteristic reddish colour when cut by grocers and consumers. These then had to be thrown away.

Limited number of trucks: In the pilot, only one truck was available to transport both onions and tomatoes from Loitoktok to Nairobi.

Poor road and weather conditions: Products that were supposed to arrive in Nairobi on Monday arrived 12 hours late due to the poor road network.

\subsubsection{Loading, offloading and packaging}

Wooden crates are very commonly used to transport produce, but they have a number of problems. Because loading and offloading were done manually, drivers were seen struggling to lift the crates even empty crates - and needed to request assistance. Often there was no soft landing of the crates due to the weight. Watermelon crates can be as heavy as $200 \mathrm{~kg}$, which was difficult for even two 
people to lift. Tomato crates weighed up to $50 \mathrm{~kg}$, which meant that women working in the pack house needed assistance from men to lift them.

Water drained easily from plastic crates when they were washed, but wooden crates absorbed the water and remained wet, leaving them prone to microbial attack. In the cold season they stayed wet for longer, increasing the risk of attack and of microbial populations remaining in the wood for a long time.

\subsubsection{Transfer and delivery}

Produce was delivered to the grocery stores free of charge, and good care was taken during transport with drivers being seen to negotiate carefully through corners and potholes to avoid collision of trays and products which may damage the produce. However, the range of products is low, with only onions, tomatoes, bananas and watermelon being available, and customers want more variety. Onions and tomatoes were brought from the field to the pack house and from pack house to grocers aboard the same truck. This can potentially negatively affect the quality of the tomatoes as onions produce chemicals that enhance ripening of tomatoes.

There is a problem with the timeliness of delivery, with grocers in Ruaka, Kinoo and Kikuyu complaining that they are losing customers due to their orders arriving late; sometimes orders did not arrive at all.

\subsubsection{Handling facilities and hygiene}

Trucks transporting foodstuff had a refrigeration system installed, which helps keep food in good condition. There was also a tank for collecting clean rainwater that was used for cleaning. After delivery of produce, crates were cleaned with soap and water. Trucks carrying onions and tomatoes were fully enclosed, which prevented dust from accumulating on the food. Trucks were washed with water and soap after offloading. However, while equipment was often washed, produce was either not cleaned or not cleaned properly. Additionally, drivers did not have any dust coats or overalls when handling food.

\subsubsection{Record-keeping}

Record-keeping systems were better from the transport stage. All customer comments and complains were recorded. When drivers arrived, they gave delivery and purchase orders to the person in charge of the pack house. All trucks had a fuel card to use for the daily assigned activities, so fuel usage could easily be tracked. The pack house recorded all products received into and dispatched from the pack house. All products that did not conform and were disposed of were measured, and records of their non-conformity and disposal were filed.

There is scope for implementing feedback received, as grocers have already commented that they prefer payment using bill pay or direct bank deposits but were still required to pay cash.

\subsubsection{Communication, marketing and customer care}

Drivers were seen talking with customers about available products and prices; that is, they were being drivers and sales people at the same time. Customers knew where drivers were at any given time, due to their constant phone communication. Drivers kept in close touch with extension officers so they knew when produce was ready to collect. From the way transporters and farmers/grocers greeted each other and talked, there seem to be very good working relationships between them. Drivers also collected information from farmers and grocery stores and passed the information to the personnel in the office and pack house. All drivers were seen handing over notes before they finished their daily shifts, ensuring this information was current and delivered in a timely fashion. 


\subsection{Pack houses}

In the pack house observations were made with regard to the following:

1. Receiving of product and quality check

2. Sorting and grading

3. Product handling and storage

4. Product dispatch

5. Hygiene and sanitation

6. Pest control

7. Waste management.

\subsubsection{Receiving of product and quality check}

Scales that were in good condition and able to tare were provided to weigh large quantities of produce. However, moving scales from one section of a pack house to another may cause inconsistencies/inaccurate measurements; this did happens as scales were moved from one pack house, where they had been used to weigh tomatoes and watermelon, to the next pack house to weigh onions. In this case, scales need to be recalibrated.

Products were sorted manually, with any damaged or non-conforming produce being recorded and disposed of. For the most part, clear written records were available of the supplier and the date that produce was harvested and delivered; these enabled retrieval of contacts when the need arose. However, there were instances of misplaced records, with some orders going missing due to misplaced paperwork. Other problems seen were that sometimes there was not enough control over quality and maturity of produce because products had not been pre-sorted in the field; the example of white watermelon was given above, and another example is that onions were received still wet from the field.

\subsubsection{Sorting and grading}

Sorting and grading were done manually, according to size to facilitate marketing. Manual sorting and grading are laborious and time-consuming. Products to be dispatched to the market were sorted first, with others sorted later.

\subsubsection{Product handling and storage}

Most products were dried naturally in the sun or in well-ventilated pack houses. Enough space was available in some pack houses so that products, such as bananas, would ripen. There was also room to store more products, but one pack house was stuffy, with poor air circulation, a leaky roof and visible mould growth. As the pack house did not have proper cooling facilities, there was no precooling of the produce nor of the transport vehicles to the desired product temperatures prior to loading. This leads to accumulation of field heat and increased metabolic activity, which means produce can spoil faster. No artificial waxing was done to replace natural waxes lost during harvesting. Tomatoes were seen shrinking. No proper drying was carried out of some produce, such as onions, which were taken to the market still wet.

Some of the problems with wooden crates were mentioned above, but another is that they are also rough on tomatoes and can damage the produce. If grocers purchase large quantities of produce, they may not be able to see that not all products conform to their preference. This is a loss to the grocer that they only realise once they examine the product before sale to their retail customers.

\subsubsection{Product dispatch}

There was a clear written list of orders that needed to be dispatched to various markets. However, not all orders were collected in time. At Ruaka market, most grocers who had placed orders did not have them delivered and they had to wait a whole day for their orders to arrive. 


\subsubsection{Hygiene and sanitation}

Water, a mop and soap were provided to clean the pack house, but disinfectants were not supplied at the pack house entry to prevent contamination from outside. Packaging materials were cleaned using water, a wash rag and soap. Water, soap and a sink were also provided to wash organic materials off produce. However, there were no clear standard operating procedure to follow during cleaning.

\subsubsection{Pest control}

A pest control method - an electronic device that produced a blue colour - was available to attract and trap fruit fly.

\subsubsection{Waste management}

Bins were made available to dispose of waste at the pack house. However, they were located within 50 metres of the pack house and attracted flies and other insects which were seen flying between the bins and the pack house.

\subsection{Grocery stores}

Grocery store keepers were asked to reflect on the strong points and challenges for the following topics in relation to the pilot:

1. Supply order placement

2. Packing and display

3. Pricing

4. Hygiene and quality

5. Payment

6. Customer service.

\subsubsection{Supply order placement}

Grocers used phone calls and text messages to place orders and to inform customers about the availability of products. However, delivery of supplies was not always reliable in terms of quantity and quality. Sometimes the wrong quantity or product was delivered; sometimes the quality was not as expected. For example, a grocer in Westlands indicated exactly the quality and quantity of tomatoes he required, but he had to sort through what was delivered to select only what met his preference. A customer in Mwimuto rejected bananas that he thought did not meet the standard he required. Other problems were delivery of rotten tomato and capsicum, wet onions, immature melons, etc.

In general, there was poor communication about supply delays and no official agreement or communication about delivery frequency. If an order was unable to be filled, no one communicated to the grocers to enable them look for alternative suppliers.

If supplies do not arrive to the grocers in time, they lose customers and do not get enough time to wipe the produce and improve the display to attract customers.

\subsubsection{Packing and display}

Onions were packaged in nets, while tomato, melons and bananas were packed in crates to avoid mixing and damage. Packaging was based on weight, but did not consider food qualities such as size, colour, sweetness, etc. Crates were often displayed well on shelves to enhance food safety and hygiene. 


\subsubsection{Pricing}

The ability to vary prices depended on the season, as prices were based on market forces. Grocers who were not able to pay cash on delivery risked not being supplied. Because of the lack of price transparency, there was a risk of consumer exploitation as evidenced by the absence of price tags on products.

\subsubsection{Hygiene and quality}

Cut fruit such as melons were covered with plastic films to prevent dust and contamination in Wastelands, Ruaka, Regen, Kinoo and Kikuyu markets. However some grocers display cut fruit uncovered, which compromised food hygiene and safety.

\subsubsection{Payment}

Payment on delivery is via cash or through Mpesa (a money transfer, payments and microfinancing service app for use on mobile phones). All grocers were required to pay for their supplies as soon as they received them, and grocers who did not have cash could not get products delivered to them. Also, there was no bill pay number, so grocers who preferred electronic money transfer - which they believed was safe and easy to verify - could not pay this way.

\subsubsection{Customer service}

Grocers generally have good relationships with customers; some grocers were even able to convince customers to buy something even when they didn't have exactly what the customer wanted. But a few grocers have poor relationship management skills; for example, in Kinoo, a grocer was upset and asked transporters if they were in their right minds for not having delivered an order, but this was due to continued outstanding debt owed by the grocer.

\subsection{Consumers}

Consumers were asked to reflect on the strong points and challenges for the following topics in relation to the pilot:

1. Supply of produce

2. Pricing

3. Food safety.

\subsubsection{Supply of produce}

Customers could easily access most products at the grocer when supply was good. However, supply was very much dependant on availability. Most grocery stores experienced inconsistency in restocking, complaining that there were no supplies in the two weeks prior to the survey, so some products were unavailable when customers wanted them. Another aspect was the limited product range, with grocers not able to provide all the commodities demanded. This limited customers' choices and preference.

\subsubsection{Pricing}

Customers had freedom of choice for their money based on quality, taste and preferences of products such as tomato and onion, and as such had the ability to trade off quality against price. Quality products are more expensive so most customers could not afford them. This was a major reason for not purchasing certified FFV even if they were available in the store.

\subsubsection{Food safety}

Customers lack knowledge about product contamination and do not notice pesticides and other contaminants on the produce such as chemical residues on tomatoes. Only in Kikuyu did a grocer say that she had a customer who noticed pesticide residue on tomatoes. 


\section{Discussion and conclusions}

We tested the hypothesis that it is possible to link farmers who produce FFV of high quality that meets strict food safety requirements with market segments such as grocery stores. This study has provided insights on the different steps needed to connect FFV with domestic market segments who want to offer higher levels of assurance in terms of food safety. Lessons learned from the pilot are summarized in this report. We explored opportunities that early adopters have to integrate food safety standards into the domestic market by adopting localg.a.p. certification.

\subsection{Catalysing a domestic market for traceable and safe fresh fruit and vegetables}

Market system organization challenges related to identifying the different business partners were experienced in implementing the pilot. While many of the actors did see the importance of a safe and traceable supply of FFV, to actually obtain commitment of the various actors to participate in the pilot took a lot of persuasion power. A change of mind-set, that a domestic market for traceable and safe fresh fruit and vegetables is actually a viable business proposition. This needs understanding the demand and viability of the system, stimulating interest and building (trustful) business relations.

With regard to the supply and demand side of the produce this remains a challenge. As farmers need to be able to plan their production cycles and be assured of a reliable market as well as decent price for the produce this needs good coordination among farmers and with the retailers. On the other hand, consumers need to be assured of a reliable supply of the produce they like to purchase. The price of the certified produce should also be within their purchasing power, as the target group, consumers from low- and middle income consumers are not prepared to pay more.

The establishment of newly formed business relationships, direct relationship between value chain actors and circumventing the wet-market, will need time to settle and build trust between the actors. The time period of the pilot is too short to be able to see if these relationship will become long-term relationships to sustain the organisation required to supply the domestic market with traceable and safe FFV.

\subsection{Contextualizing standards for the domestic fresh fruit and vegetables value chain}

To identify the most suitable standard for the domestic horticulture value chain, several discussions between Tradecare, as the intermediary in the pilot, and GLOBALG.A.P. representatives were needed to understand how to best to meet the requirements of the standard. localg.a.p. was chosen because, at foundation level, it focuses primarily on food safety requirements, and less so on health and safety and environmental sustainability dimensions.

A prerequisite for the diffusion of good practices is a safety standard. Kenya has adopted a national standard developed by the government called KS1758. As the accompanying traceability system, HTS, was developed with a focus on the export markets, there is a gap on how to deploy standards and systems to assure food safety in the local markets and be compatible with the domestic horticulture supply chain that the pilot aimed to support (Chemeltorit, 2018). To incorporate the eProd system into the pilot was deemed to be more suitable however it did not fully fit the bill. The main challenge was the specifics of the horticulture sector and pilot setting. eProd did, at the time of the pilot, not accommodate the registration of multiple crops. Therefore, manual labelling was used as a simpler 
system for the pilot, although it also had implementation challenges. Tradecare had to negotiate with GLOBALG.A.P. to make their localg.a.p. bookmarking account - an online secure database that stores information on FFV suppliers - more in line to GLOBALG.A.P. bookmarking so that more product information could be publicly searched. This to be able to assign the localg.a.p. number as the traceability identifier to the produce (labelling) that would be part of the scheme (market) thereby ensuring accountability, traceability and transparency for the grocery stores (seller) and assure the consumers.

In the long-term a suitable electronic system that serves the needs of the domestic horticulture supply chain is still required as manual labelling has a risk of losing relevant information in the chain such a missing or wrongly numbered labels.

Lobby and advocacy for better adaptation to the local context were clear contributions of the pilot project and the work of Tradecare through Mazao Safi. Some of these outcomes were:

- having the possibility to adapt to the complexity of the supply chain and avoid having a database with farmer information, which proved to be difficult during the pilot project. For this, GLOBALG.A.P. agreed that it did not require the fully customized solution but would allow the use of the localg.a.p. ready-to-use solution

- making the bookmarking account public which helped improve the public profile of companies, rather than individual farmers, that are adopting localg.a.p. certification. This helped facilitate the implementation of the standard. A public search visibility tool was used for both the Foundation and the Intermediate levels (see Box 1), which may help to create trust in localg.a.p. certified systems

- having approval from GLOBALG.A.P. to be exempt from paying for membership and allowing bookmarking for companies that want to initiate localg.a.p. programmes, as well as the possibility of not being a programme owner, as GLOBALG.A.P. took on that role

- reducing the need to have contract agreements and letters of support for a localg.a.p. ready-to-use solution; this reduced the burden of extra documentation

- the engagements with GLOBALG.A.P. gave farmers the option of choosing only the Foundation or Intermediate level, so they could stay on either of these first two levels and be accepted by the market. In addition, it helps to increase flexibility, so that farmers who wish to move from one level to the next would not be bound to any specific time frame.

\subsection{Conclusions}

The pilot delivered insights on the different steps and factors that are essential if similar endeavours are to be promoted in the Kenyan context. The key learnings of the pilot are summarized as follow:

- The development of a market that offers products that seek to meet high quality and safety standards needs to have incentives for the different value chain actors to encourage them to make the needed investments. The incentives are linked to assuring consistent volumes for the market and provision of a (good) price that reflects a fair value distribution.

- The ambition to introduce a food safe market innovation in the domestic FFV supply chain requires pulling in substantial upfront investments in the start-up phase and later into actual deployment. This pilot provides some reflection on what these investments are in the start-up phase and some of the opportunities and challenges faced in mobilizing them. The main challenges at farm level included the difficulties in acquiring quality seeds and the need for more technical support on irrigation, proper fertilization and pest management. In terms of deployment, the use of less hazardous pesticides and the proper disposal of pesticide containers were the main bottlenecks to safer production.

- Developing quality requirements together with the participating actors was key to ensuring better understanding of their needs and matching with the reality of Kenyan farmers.

- The introduction of a suitable standard, in this case localg.a.p., that allows farmers to comply to food safety requirements and one they can relatively easily adopt is a lengthy process. This as it needs both extensive administrative procedures as well as extensive training of the farmers and awareness raising of other actors in the horticulture value chain.

- As a standard can only work appropriate when the required checks and balances are in place, such as a suitable traceability system and for instance checks of pesticides residues, the MRLs, supporting 
services need to be in place as well. With regards to the traceability system the challenge was that a ready for use system available on the market did not fully support the needs of the pilot. The localg.a.p. bookmarking system offered an alternative however in the long-term a more tailor-made traceability system that suits the needs of the sector is till required. With regards to testing of MRLs the challenges were multiple, both the costs of the tests as well as the capacity of the laboratories, both hampered the execution of the analysis.

- Provision of technical extension services through Mazao Safi was key to supporting farmers to deliver high quality and safely produced FFV by working on the critical factors of production and helping farmers to realize improved and sustainable profits.

- Even with the pivotal role and agency of Tradecare through Mazao Safi, there were challenges in meeting grocery store demands. This suggests that better follow-up to match volumes and demand should be in place as well as better monitoring of the pricing mechanisms to take into account different regional contexts and ensure fair prices.

- The pilot results showed that there are challenges to do with the transparency of market dynamics. Farmers were unsatisfied with low prices at the farm gate, and the differences in costs of production across regions were not fully compensated for in the prices received by farmers. This suggests that better price setting mechanisms would benefit farmers.

- From the learnings about transportation and product packaging, it was found that to ensure good quality and traceability a structural assurance model must be in place to guarantee that produce is handled carefully and skills of personnel are improved to given them adequate knowledge on quality parameters, particularly the right timing for harvesting a product.

- As the intermediary actor facilitating this market development, Mazao Safi played a very important role in identifying matches between farmers and grocers. This coordination role is paramount to the development of such a system in the current context of FFV production and trade in Kenya.

- The coordinating role of Tradecare was essential in order to bring actors together to discuss the needs of the grocers and the feasibility of the farmers delivering what was needed. The process of coordination included support for implementation of localg.a.p. requirements as well as technical advice in terms of GAPs needed to meet the needs of the market.

- As it was an exploratory idea, it was not apparent how much capital would be needed for start-up, and the nature of the risks was also unclear. Therefore, mobilizing the investment needed was unstructured and generally experimental. The initial pilot idea was supported through the $3 R$ Kenya project. Tradecare sought out additional support from other development partners while transitioning the pilot into a business model. Tradecare also made some investments through its own finances and some commercial loans (infrastructure, logistics). 


\section{References}

AFA--Agriculture and Food Authority. (2019). Horticulture Validated Report 2017-2018, Agriculture and Food Authority, Nairobi. https://agricultureauthority.go.ke/wpcontent/uploads/2020/02/VALIDATE-REPORT-2017-2018-1.pdf

Aung, M. M., and Chang, Y. S. (2014). Traceability in a food supply chain: Safety and quality perspectives. Food Control, 39(C), 172-184. http://doi.org/10.1016/j.foodcont.2013.11.007

Chemeltorit, P., Saavedra Y., and Gema, J. (2018). Food traceability in the domestic horticulture sector in Kenya: An overview. Practice brief 005. Wageningen University \& Research. Wageningen.

Gema, J., Keige, J., Chemeltorit, P., Ngetich, T., Moreno Echeverri, I., Saavedra Gonzalez, Y., and Koomen, I. (2018). Catalysing food safety in the domestic horticulture sector in Kenya: The potential link between export production and evolving domestic supply chains. Wageningen Centre for Development Innovation, Wageningen University \& Research. Report WCDI-18-051. Wageningen.

Inonda, R., Njage, E., Ngeranwa, J., and Mutai, C. (2015). Determination of pesticide residues in locally consumed vegetables in Kenya. African Journal of Pharmacology and Therapeutics, 4(1), 1-6.

Kutto, E.K., Ngigi, M.W., Karanja, N., Kangethe, E., Bebora, L.C., Lagerkvist, C.J.L., Muthia, P.G., Njagi, L.W. and Okello, J.J. (2011). Bacterial contamination of Kale (Brassica oleracea acephala) along the supply chain in Nairobi and its environment. East African Medical Journal, 88(2), 46-53.

Lenné, J.M., Pink, D.A.C., Spence, N.J., Ward, A.F., Njuki, J., and Ota, M. (2005). The Vegetable Export System: A Role Model for Local Vegetable Production in Kenya. Outlook on Agriculture, 34(4), 225-232. https://doi.org/10.5367/000000005775454689

Lenné, J.M., and Ward, A.F. (2010). Improving the Efficiency of Domestic Vegetable Marketing Systems in East Africa: Constraints and Opportunities. Outlook on Agriculture, 39(1), 31-40. https://doi.org/10.5367/000000010791169952

Matui, M.S., Saavedra Gonzalez, Y., Gema, J., and Koomen, I. (2016). From aid to sustainable trade: driving competitive horticulture sector development; A quick scan of the horticulture sector. Wageningen Centre for Development Innovation, Wageningen University \& Research. Report 3RKenya-16-03/CDI-16-045. Wageningen.

Mithöfer, D., Nang'ole, E., and Asfaw, S. (2008). Smallholder Access to the Export Market: The Case of Vegetables in Kenya. Outlook on Agriculture, 37(3), 203-211. https://doi.org/10.5367/000000008785915476

Ogweni, T. (2019). Positioning food quality and safety for fresh vegetables - Products, Promotion, Placement and Pricing. Internship Report, Wageningen University \& Research, Wageningen.

Onyango, C.M., and Kunyanga, C. (2013). Evaluation of the safety of selected fruits and vegetables sold in the domestic markets in Kenya. Consultancy report - United Nations (UN).

Route to Food. (2019). Pesticides in Kenya: Why our health, environment and food security are at stake. https://routetofood.org/wp-content/uploads/2019/08/RTFI-White-Paper-Pesticides-inKenya.pdf

Yen, E., Hoffmann, V., Grace, D., Karugia, J., and Aguda, R. (2018). Food safety in Kenya: Focus on fruits and vegetables. Project Note. Washington, DC: International Food Policy Research Institute (IFPRI). http://ebrary.ifpri.org/cdm/ref/collection/p15738coll2/id/132321 


\section{Appendix 1 Product specifications}

\begin{tabular}{|c|c|}
\hline Tradecare & Farmers \\
\hline Product description & This entails the nutritional benefits of the product. \\
\hline Managing quality at farm level & $\begin{array}{l}\text { This outlines the basic farm practices that need to be implemented by the } \\
\text { farmer to ensure quality and safety of the product. }\end{array}$ \\
\hline Maturity indicator & $\begin{array}{l}\text { These are the indicators of when the product is mature and ready for } \\
\text { harvesting e.g. the size of the product and also based on market demand. }\end{array}$ \\
\hline Recommended mode of harvesting & $\begin{array}{l}\text { Includes recommended harvesting tools and how to handle products when } \\
\text { harvesting to prevent damage and bruising of the product or attack by } \\
\text { diseases and recommended storage containers/material for some of the } \\
\text { products. }\end{array}$ \\
\hline Holding at the farm: & $\begin{array}{l}\text { This provides a detailed description of post-harvest handling at farm level } \\
\text { before packaging, including recommended storage methods at the farm while } \\
\text { awaiting transportation. }\end{array}$ \\
\hline Packaging at farm level & $\begin{array}{l}\text { This includes how to stack the products and the recommended storage } \\
\text { material/equipment to use. }\end{array}$ \\
\hline Transportation & $\begin{array}{l}\text { This includes the mode of product storage, transportation most favourable } \\
\text { time to transport, how to unload the storage containers to prevent damage of } \\
\text { the product. }\end{array}$ \\
\hline Pack house operations & $\begin{array}{l}\text { This details the procedures followed from the time the products are received at } \\
\text { the pack house reception, to cleaning, sorting, grading and drying. }\end{array}$ \\
\hline Quality control & $\begin{array}{l}\text { This is a description of quality indicators both in general and for the different } \\
\text { grades with regard to the appearance of the product (size colour, texture, } \\
\text { shape and free from mechanical damage and other defects such as rotting or } \\
\text { deterioration), taste, smell, specific pests that the product should be free of, } \\
\text { weight of the product and post-harvest handling indicators such as cleanliness, } \\
\text { temperature and pH of the post-harvest water and as well as the level of } \\
\text { maintenance of the harvesting/cutting equipment. }\end{array}$ \\
\hline Storage temperature & $\begin{array}{l}\text { This entails the temperature }\left({ }^{\circ} \mathrm{C}\right) \text { of the storage facility, humidity }(\%) \text { and } \\
\text { keeping period. }\end{array}$ \\
\hline Packaging for wholesale & $\begin{array}{l}\text { This entails the way in which the products are packed and stacked, the } \\
\text { packaging equipment/material, as well as the pack rates (e.g. in crates or } \\
\text { bunches), ready for wholesale. }\end{array}$ \\
\hline Packaging for retail & This entails details of the pack rates for the products, ready for retail. \\
\hline
\end{tabular}




\section{Appendix 2 Volumes project for the different products per region}

\begin{tabular}{|c|c|c|c|c|}
\hline Tradecare & Farmers & Transporters & Grocers & Support actors \\
\hline Code & Product & Worst case & Most likely & Best case \\
\hline VA002 & Amaranth & 100 & 200 & 250 \\
\hline FA001 & Avocadoes & 500 & 1,000 & 1,250 \\
\hline VC001 & Cabbages & 1,500 & 3,000 & 3,750 \\
\hline VC002 & Capsicum & 250 & 500 & 625 \\
\hline VG002 & Green banana & 1,000 & 2,000 & 2,500 \\
\hline VK001 & Kales & 250 & 500 & 625 \\
\hline FP001 & Passion fruits (Local) & 100 & 200 & 250 \\
\hline VP003 & Pumpkins & 1,000 & 2,000 & 2,500 \\
\hline FB001 & Ripe Banana & 1,000 & 2,000 & 2,500 \\
\hline VS002 & Spinach & 400 & 800 & 1,000 \\
\hline VT001 & Tomatoes & 1,500 & 3,000 & 3,750 \\
\hline FT002 & Tree tomatoes & 100 & 200 & 250 \\
\hline FW001 & Watermelon & 2,500 & 5,000 & 6,250 \\
\hline \multirow[t]{2}{*}{ FY001 } & Yellow passion & 100 & 200 & 250 \\
\hline & $\begin{array}{l}\text { Total projected } \\
\text { production value }\end{array}$ & $10,300.00$ & $20,600.00$ & $25,750.00$ \\
\hline \multicolumn{5}{|c|}{ Kirinyaga Hub } \\
\hline Code & Product & Worst case & Most likely & Best case \\
\hline VA002 & Amaranth & 250 & 500 & 625 \\
\hline FA001 & Avocadoes & 100 & 200 & 250 \\
\hline VC001 & Cabbages & 500 & 1,000 & 1,250 \\
\hline VC002 & Capsicum & 300 & 600 & 750 \\
\hline VG002 & Green banana & 3,500 & 7,000 & 8,750 \\
\hline VG003 & Green Maize & 750 & 1,500 & 1,875 \\
\hline VK001 & Kales & 100 & 200 & 250 \\
\hline VP003 & Pumpkins & 250 & 500 & 625 \\
\hline FB001 & Ripe Banana & 1,000 & 2,000 & 2,500 \\
\hline VS002 & Spinach & 350 & 700 & 875 \\
\hline VS003 & Spring onion & 100 & 200 & 250 \\
\hline \multirow[t]{2}{*}{ VT001 } & Tomatoes & 750 & 1,500 & 1,875 \\
\hline & $\begin{array}{l}\text { Total projected } \\
\text { production value }\end{array}$ & $7,950.00$ & $15,900.00$ & $19,875.00$ \\
\hline \multicolumn{5}{|c|}{ Machakos Hub } \\
\hline Code & Product & Worst case & Most likely & Best case \\
\hline VC002 & Capsicum & 400 & 800 & 1,000 \\
\hline VG001 & Garden peas & 100 & 200 & 250 \\
\hline VG002 & Green banana & 750 & 1,500 & 1,875 \\
\hline VG003 & Green Maize & 2,000 & 4,000 & 5,000 \\
\hline VK001 & Kales & 1,500 & 3,000 & 3,750 \\
\hline VS002 & Spinach & 150 & 300 & 375 \\
\hline VT001 & Tomatoes & 1,500 & 3,000 & 3,750 \\
\hline FB001 & Ripe Banana & 500 & 1,000 & 1,250 \\
\hline FM001 & Mangoes & 500 & 1,000 & 1,250 \\
\hline \multirow[t]{2}{*}{ FO001 } & Oranges & 250 & 500 & 625 \\
\hline & $\begin{array}{l}\text { Total projected } \\
\text { production value }\end{array}$ & $7,650.10$ & $15,300.20$ & $19,125.25$ \\
\hline
\end{tabular}




\section{Appendix 3 Survey Questionnaires}

\section{A. Farmers Questionnaire}

My name is ............ I am collecting data on behalf of $3 \mathrm{R}$ project. The data collected will be used to improve supply of fresh fruits and vegetables. I assure you of confidentiality and that the responses you give will not be disclosed to other parties.

Ask the respondent for consent. If yes, proceed. Else go to the next respondent.

1. Ask and indicate name of the farmer

2. Indicate gender

3. Ask and record age bracket

4. Ask and record education level

5. Ask and select appropriate option

6. Ask and select appropriate employment status

7. Ask and indicate location

8. Ask and indicate main crop

9. Ask and indicate other crops grown

10. Make observations and interview farmer about farm practices focussing on use of pesticides, quality of water and other inputs. Include harvesting and postharvest handling

11. From the previous questions, does the farmer produce in a safe manner?

12. Assess and record to what extent the farmer observes localg.a.p requirements

13. Overall does the farmer observe localg.a.p

14. Does the famer maintain records?

15. If yes, indicate the records maintained. Add any comments

16. Ask and check if the farmer aggregates produce

17. If yes, provide details about aggregation

18. Check how the farmer deals with other actors

19. Check how the farmer communicate with other actors. Verify with the other actors

20. Check production schedules and produce demand. Record the findings

21. Is the supply reliable?

22. What have you learnt from the pilot?

23. What the challenges have you faced when adopting localg.a.p.?

24. What difference have you experienced between localg.a.p. and GlobalG.A.P.?

25. What motivates you to take part in a traceable supply chain?

26. What has changed in the way you are organized since the start of the pilot?

27. What challenges do you face in record-keeping/data collection? And why?

28. What challenges do you face in keeping segregated products and keeping traceability

29. What challenges do you face in monitoring the traceability and delivering product specifications?

30. What challenges do you face in organizing the trade of products with higher food safety assurance?

31. What challenges do you face in dealing with other actors in the trade? 
32. How is trade organized and how different it is as compared before the pilot?

33. What is your role in the supply chain and has your role changed since the pilot?

34. To what extend are you (farmer) empowered with the new trade relationship?

35. What are the services do you need as a farmer to be able to ensure good traceable products?

36. What support do you need as a collector to be able to keep traceability and avoid commingling?

37. What are the economic implications of adopting localg.a.p and e-production?

38. What are the necessary investments needed to keep traceable products for farmers?

That is the end. Thank the respondent for the time.

\section{B. Transporter Questionnaire}

My name is ............ I am collecting data on behalf of $3 R$ project. The data collected will be used to improve supply of fresh fruits and vegetables. I assure you of confidentiality and that the responses you give will not be disclosed to other parties.

Ask the respondent for consent. If yes, proceed. Else go to the next respondent.

1. Ask and indicate name of the transporter

2. Are you employed or this is your own business?

3. Indicate gender

4. Ask and record age bracket

5. Ask and record education level

6. Ask and select appropriate option

7. Indicate location where the transporter is based

8. Indicate who the main client is

9. Indicate other clients served by the transporter

10. Describe how the transporter ensures hygiene of the produce during transport?

11. From the previous, does the transporter ensure produce hygiene?

12. Does the transporter maintain records?

13. If yes, indicate the records maintained. Add any comments

14. Describe how the transporter deal with other actors

15. Describe how the transporter facilitates communication among the actors

16. Describe how transport is organized including planned schedules and actual pickups. Counter check with farmers and grocery stores

17. Is the transporter reliable?

18. Is the transport timely? Counter check with farmers and grocery stores

19. What support do you need as a collector to be able to keep traceability and avoid commingling?

20. What are the economic implications of adopting localg.a.p. and e-production?

21. What are the necessary investments needed to keep traceable products for collectors?

That is the end. Thank the respondent for the time. 


\section{Checklist for observations at the pack house}

- How is the produce received at the pack house?

- What quality checks are carried out?

- How is waste managed?

- How is the hygiene/sanitation status of the pack house?

- Are the following practices carried out? If yes, how?

- Waxing

- Drying

- Ripening

- Pre-cooling

- How is sorting and grading done

- How are pests controlled?

- How packaging undertaken?

- How are the products stored?

\section{Grocers Questionnaire}

My name is ............ I am collecting data on behalf of $3 R$ project. The data collected will be used to improve supply of fresh fruits and vegetables. I assure you of confidentiality and that the responses you give will not be disclosed to other parties.

Ask the respondent for consent. If yes, proceed. Else go to the next respondent.

1. Indicate the name of the grocery

2. Indicate gender of supervisor of FFV section

3. Ask and record age bracket of supervisor of FFV section

4. Ask and record education level of supervisor of FFV section

5. Ask and indicate location

6. List the main products stocked

7. Describe how the grocery promotes demand for safe produce

8. Describe how the display in the grocery promotes hygienically

9. You may capture an image to illustrate display

10. Check how the grocery deals with other actors

11. Describe how pricing is done by the grocery and indicate if transparent

12.

13. Describe how the stores places orders

14. Indicate if orders are placed in a timely manner

15. Describe how the stores makes payment indicating time taken to pay suppliers

16. Indicate if payments are made in a timely manner

17. Describe how the grocery promotes safety of produce to consumers

18. What are the economic benefits do you get as grocery store by sourcing higher quality products?

19. What are the economic implications of adopting localg.a.p. and e-production?

20. What are the necessary investments needed to keep traceable products for grocery stores?

That is the end. Thank the respondent for the time. 


\section{E. Consumers Questionnaire}

My name is ............ I am collecting data on behalf of 3R project. The data collected will be used to improve supply of fresh fruits and vegetables. I assure you of confidentiality and that the responses you give will not be disclosed to other parties.

1. Ask the respondent for consent. If yes, proceed. Else go to the next respondent.

2. What is the name of the grocery store

3. Where is the location of the grocery store

4. What is the gender of the customer

5. What is the age bracket of the customer

6. What is the education level of the customer

7. Which products does the customer buy from this grocery

8. How often does the customer come to this store to buy FFV

9. Why does/doesn't the customer come often to the store?

10. Which factors does the consumer consider when buying FFV

11. How do the consumers assess safety when buying FFV?

12. How do the consumers assess quality when buying FFV?

13. On the scale provided, how does the customer rate the price of FFV in the grocery? 0: Very Low, 10 Very High

14. On the scale provided, how likely is the customer to pay a higher price for better quality of FFV? 0: Unlikely, 10 likely

That is the end. Thank the respondent for the time. 
Wageningen Centre for Development Innovation

Wageningen University \& Research P.O. Box 88

6700 AB Wageningen

The Netherlands

$\mathrm{T}+31(0) 317486800$

www.wur.eu/cdi

Report WCDI-20-117

3R Report 016
Wageningen Centre for Development Innovation supports value creation by strengthening capacities for sustainable development. As the international expertise and capacity building institute of Wageningen University \& Research we bring knowledge into action, with the aim to explore the potential of nature to improve the quality of life. With approximately 30 locations, 5,000 members of staff and 12,000 students, Wageningen University \& Research is a world leader in its domain. An integral way of working, and cooperation between the exact sciences and the technological and social disciplines are key to its approach. 



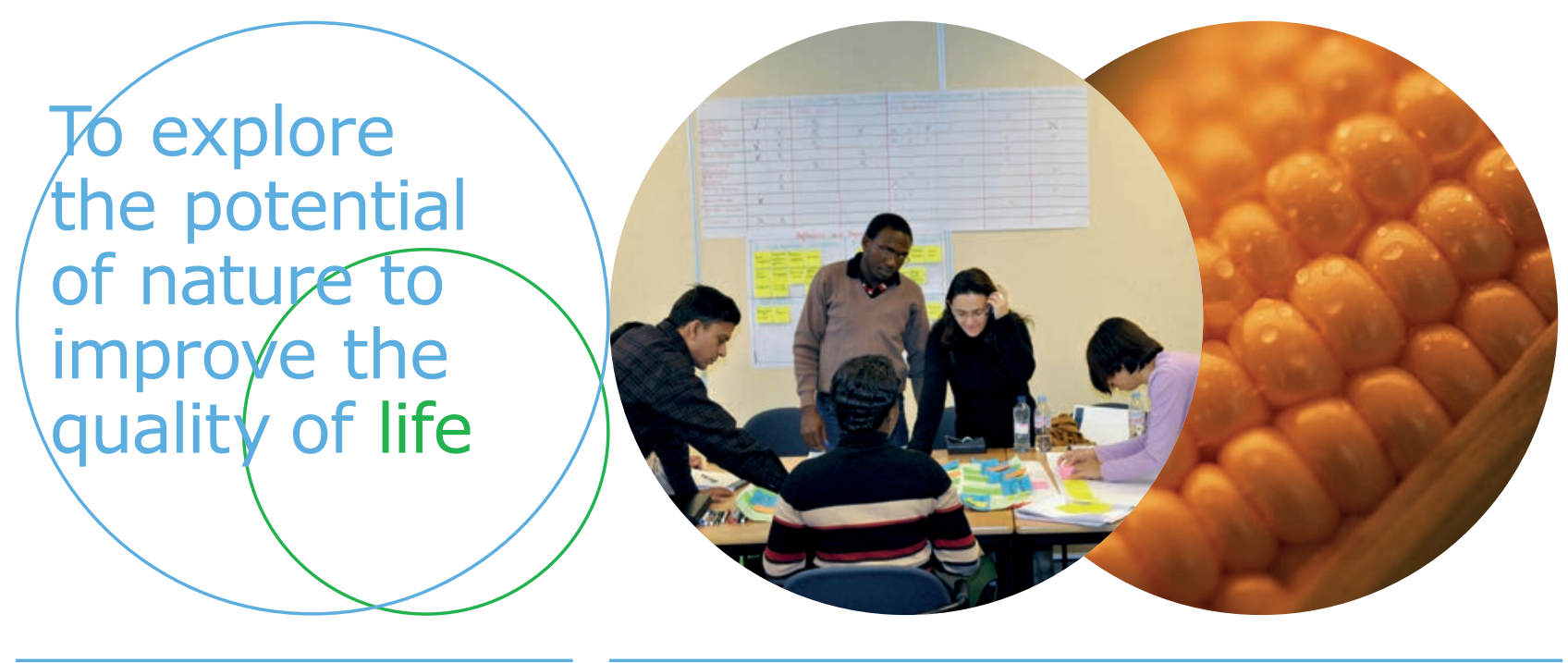

Wageningen Centre for Development Innovation Wageningen University \& Research P.O. Box 88 $6700 A B$ Wageningen The Netherlands $\mathrm{T}+31$ (o)317 4868 oo www.wur.eu/cdi

Report WCDI-20-117 3R Report 016
Wageningen Centre for Development Innovation supports value creation by strengthening capacities for sustainable development. As the international expertise and capacity building institute of Wageningen University \& Research we bring knowledge into action, with the aim to explore the potential of nature to improve the quality of life. With approximately 30 locations, 5,000 members of staff and 12,000 students, Wageningen University \& Research is a world leader in its domain. An integral way of working, and cooperation between the exact sciences and the technological and social disciplines are key to its approach. 